\title{
Synthesis of multipod-like silica/polymer latex particles via nitroxide-mediated polymerization-induced self-assembly of amphiphilic block copolymers
}

\author{
X. G. Qiao, P-Y. Dugas, B. Charleux, M. Lansalot, E. Bourgeat-Lami*
}

Université de Lyon, Univ. Lyon 1, CPE Lyon, CNRS, UMR 5265, Laboratoire de Chimie, Catalyse, Polymères et Procédés (C2P2), LCPP group, 43, Bd. du 11 Novembre 1918, F69616 Villeurbanne, France.

\begin{abstract}
We report the first nitroxide-mediated synthesis of multipod-like silica/polymer latexes by polymerization-induced self-assembly (PISA) of amphiphilic block copolymers in aqueous emulsion. A water-soluble brush-type PEO-based macroalkoxyamine initiator composed of poly(ethylene oxide) methacrylate and a small amount of styrene (P $\left.\left(\mathrm{PEOMA}_{950}\right)_{12}-\mathrm{co}-\mathrm{S}_{1}\right]-$ SG1, $M_{\mathrm{n}}=11700 \mathrm{~g} \mathrm{~mol}^{-1}$ and $\left.M_{\mathrm{w}} / M_{\mathrm{n}}=1.11\right)$ was synthesized and physically adsorbed on the surface of silica particles through hydrogen bonding interactions. The adsorbed macroalkoxyamine initiator was subsequently employed to initiate the emulsion polymerization of $n$-butyl methacrylate with a small amount of styrene under mild conditions $\left(85^{\circ} \mathrm{C}\right)$. Kinetic analysis indicates that the polymerizations exhibit the same behavior (i.e. the same reaction rates and the same level of control) as those reported in our previous work in the absence of silica under otherwise similar experimental conditions (Qiao et al. Macromolecules 2013, 46, 4285-4295). This observation is fully consistent with a PISA process taking place at the silica surface. The resulting self-assembled block copolymers formed polymer nodules randomly distributed around the central silica spheres. Varying the macroinitiator concentration or the silica particle size enabled the successful formation of hybrid particles with dumbbell-, daisy- or raspberry-like morphologies using this new surface-PISA process.
\end{abstract}

Keywords: Silica, controlled radical polymerization, emulsion polymerization, polymerization-induced self-assembly, amphiphilic block copolymers, nitroxide-mediated polymerization, poly(ethylene oxide) methyl ether methacrylate, multipod-like morphology 


\section{INTRODUCTION}

Colloidal particles with complex shapes such as triangles, pyramids, rods, cubes, nanodisks, star-like, peanuts and other sorts of exotic geometries have attracted considerable attention in the past few years. ${ }^{1-4}$ Such complex particles with well-defined compositions and morphologies can find applications in many areas of colloid science and are very promising building blocks for the elaboration of functional advanced materials. ${ }^{5-7}$ Among them, multipod-like particles with a controlled number of pods (e.g., dumbbells, dipods, tripods and beyond), have been the subject of intensive research. ${ }^{8-15}$ For instance, colloidal polymerpolymer dumbbells have been produced by controlled phase separation in seeded emulsion polymerization. ${ }^{9-11}$ Colloidal polymeric clusters with a precisely defined geometry have been generated by confining latex particles to water-in-oil emulsion droplets and subsequent oil removal, a process pioneered by Velev et al. ${ }^{12}$ in 1996 and further extended to a variety of colloidal systems ${ }^{13-16}$ including inorganic particles ${ }^{15}$ and binary mixtures of organic and inorganic colloids. ${ }^{16}$

Organic/inorganic particles have received increasing interest in the recent literature. ${ }^{17}$ Our group has been particularly active in this area, with special attention being focused on the synthesis of polymer/silica biphasic particles. ${ }^{18-22}$ Such particles can be obtained by seededgrowth emulsion polymerization using methacryloxy methyl triethoxysilane (MMS) ${ }^{18-19}$ or poly(ethylene oxide) methyl ether methacrylate (PEOMA)- ${ }^{20}$ functionalized silica particles as seeds. Depending on the reaction conditions, core-shell particles or highly regular silica/polymer assemblies (namely, tetrapods, hexapods, octopods and so on), were successfully generated. ${ }^{22}$ For both types of functionalized silica particles, however, the use of appropriate surfactants or mixtures of surfactants was necessary to stabilize the so-formed multipod colloids and control their morphologies. In particular, morphology of the obtained 
structures was shown to be strongly dependent on the nature of the surfactant and on the ratio between the number of silica seeds and the number of growing nodules, the latter of which is determined by the silica particle size and the surfactant concentration. ${ }^{19}$

Recently, a surfactant-free aqueous emulsion polymerization technique was developed in which self-stabilized polymer latexes are produced through polymerization-induced selfassembly (PISA) of amphiphilic block copolymers. ${ }^{23-47}$ The PISA process involves chain extending a hydrophilic polymer precursor prepared via controlled radical polymerization with hydrophobic monomer(s) to form amphiphilic chains which self-assemble into spherical nano-objects or more complex morphologies depending on reaction conditions. The notable advantages of this process are the absence of low molar mass surfactant in the suspension, the simplicity of a one-pot aqueous process applicable to a wide number of monomers and the ability to achieve a variety of morphologies at high solids content without the aid of an organic co-solvent. While initially developed for the synthesis of pure polymeric particles using nitroxide-mediated polymerization $(\mathrm{NMP})^{25-30}$ or reversible addition-fragmentation chain transfer (RAFT), ${ }^{31-47}$ the PISA process has been recently extrapolated to the synthesis of organic/inorganic particles. ${ }^{48-55}$ The reported strategy, pioneered by Hawkett et al., ${ }^{48}$ relies on the adsorption of amphipathic macroRAFT agents onto inorganic particles to encourage the emulsion polymerization to occur at their surface, and has so far been employed for the encapsulation of titanium dioxide pigments, ${ }^{48}$ quantum dots, ${ }^{49}$ gibbsite clay platelets, ${ }^{50}$ carbon nanotubes $^{51-52}$ and cerium dioxide ${ }^{53}$ particles. NMP, however, has not yet been employed for the synthesis of organic/inorganic colloids in aqueous dispersed media following this strategy. Furthermore, the aforementioned articles are mainly dedicated to the formation of polymer-encapsulated particles and none of them describe the synthesis of multipod-like colloids. 
In this work, we report the first surfactant-free NMP-mediated synthesis of silica/polymer multipod-like particles through emulsion polymerization. Our strategy involves the use of a well-defined hydrophilic PEOMA-based macroalkoxyamine ${ }^{30}$ adsorbed on the surface of silica particles prior to polymerization, and does not require any chemical modification nor the use of molecular surfactants. The adsorbed macroinitiator was chain-extended in water to generate hybrid particles according to the PISA process. The resulting hybrid colloids were characterized by cryo-transmission electron microscopy to give insight into the effect of polymerization conditions on particle morphology for various initial silica particle sizes. In addition, the polymerization kinetics was studied to demonstrate the living character of the polymerization and the successful formation of block-copolymers, highlighting the potential of this new surface-PISA process for the synthesis of colloidal nanocomposites.

\section{EXPERIMENTAL SECTION}

Materials. The monomers, styrene (S, 99\%, Acros), n-butyl methacrylate (BMA, 99\%, Aldrich) and poly(ethylene oxide) methyl ether methacrylate $\left(\mathrm{PEOMA}_{950}, M_{\mathrm{n}}=950 \mathrm{~g} \mathrm{~mol}^{-1}\right.$, Aldrich) were used as received. The $N$-(2-methylpropyl)- $N$-(1-diethylphosphono-2,2dimethylpropyl)-O-(2-carboxyl prop-2-yl) hydroxylamine initiator (BlocBuilder $\left.{ }^{\circledR}, 99 \%\right)$ and $N$-tert-butyl- $N$-(1-diethyl phosphono- 2,2-dimethylpropyl) nitroxide (SG1, 85\%) were kindly supplied by Arkema. Ethanol (Prolabo, 99.9\%), L-arginine ( $\geq 98.5 \%$, Aldrich), hydrochloric acid $(\mathrm{HCl}, 0.1 \mathrm{M}$ solution in water), ammonium hydroxide $(28 \% \mathrm{wt} / \mathrm{wt}$ aqueous ammonia solution, Aldrich) and tetraethyl orthosilicate (TEOS, $\geq 99.0 \%$, Aldrich) were used without further purification. The Klebosol 30N50 commercial silica sol was kindly supplied by Clariant (France) as a $31.5 \mathrm{wt} \%$ solids aqueous colloidal suspension. It was centrifuged at 15 $000 \mathrm{rpm}$ for 15 minutes to remove the very small particles (diameter $\leq 50 \mathrm{~nm}$ ) present in the 
sample. Its characteristics are shown in Table 1 (S2). Deionized water (Purelab Classic UV, ElgaLabWater) was used for all experiments.

Silica particle synthesis. Silica particles with diameters ranging from 30 to $450 \mathrm{~nm}$ and narrow size distributions were synthesized using three different procedures. First, ultrafine, highly monodisperse silica particles were synthesized using the two-phase process of Hartlen et al. ${ }^{56}$ In this process, an immiscible organic top layer of TEOS, was left diffusing into an aqueous solution of amino-acid catalyst, leading to a slow increase in the solution supersaturation and subsequent formation of tiny silica particles with a very narrow size distribution. ${ }^{56-57}$ However, in contrast with previous reports, no inert oil (i.e., octane or cyclohexane) was employed in the present system. In a typical procedure, L-arginine (Aldrich, $26.3 \mathrm{mg}, 6 \mathrm{mmol} \mathrm{L}{ }^{-1}$ ) was first diluted in deionized water (25 g), charged into the reactor and kept stirring for several minutes with a stirring bar. Once the solution temperature reached $60{ }^{\circ} \mathrm{C}, 4.0 \mathrm{~mL}$ of TEOS was carefully introduced on top of the reactor leading to two separate phases. The stirring rate was fixed at $250 \mathrm{rpm}$ so that the top organic layer was left almost undisturbed and the water phase could be well mixed. The mixture was stirred at 60 ${ }^{\circ} \mathrm{C}$ for $72 \mathrm{~h}$ to form $30 \mathrm{~nm}$ diameter silica particles (S1, Table 1). These silica particles were then used as seeds to generate larger monodisperse particles according to the so-called seedregrowth process. ${ }^{58-60}$ In a typical regrowth reaction, a certain amount of silica seeds (S1, $0.02 \mathrm{M})$ was gently dispersed in an ethanol solution containing water and ammonia (0.3 M). Upon uniform mixing, $42.0 \mathrm{~g}$ of TEOS $\left(1.0 \mathrm{~mol} \mathrm{~L}^{-1}\right)$ was added. The mixture was stirred at room temperature for $24 \mathrm{~h}$ to obtain $136 \mathrm{~nm}$ silica particles (S3, Table 1). Finally, larger particle sizes were obtained using the conventional Stöber process in batch. ${ }^{61}$ Typically TEOS $\left(29.12 \mathrm{~g}, 0.2 \mathrm{~mol} \mathrm{~L}^{-1}\right)$, deionized water $\left(75.6 \mathrm{~g}, 6 \mathrm{~mol} \mathrm{~L}^{-1}\right)$ and absolute ethanol $(450 \mathrm{~g}$, $13.9 \mathrm{~mol} \mathrm{~L}^{-1}$ ) were mixed, charged into a $1 \mathrm{~L}$ round bottom flask and stirred for $20 \mathrm{~min}$. A 
mixture of ammonia and ethanol (ammonia solution diluted in $15 \mathrm{~g}$ of absolute ethanol, 0.5 mol $\mathrm{L}^{-1}$ ) was introduced in one portion and the solution stirred for at least $24 \mathrm{~h}$ at room temperature. The ammonia concentration was either $0.3 \mathrm{M}$ to $0.6 \mathrm{M}$, leading to $230 \mathrm{~nm}$ and $440 \mathrm{~nm}$ silica spheres, respectively (S4 and S5, Table 1).

\section{Synthesis of P[(PEOMA $\left.\left.{ }_{950}\right)_{12}-c o-S_{1}\right]-S G 1$ brush-type macroalkoxyamine initiator. The} brush-type PEOMA-based macroalkoxyamine initiator (P[(PEOMA $\left.\left.\left.{ }_{950}\right)_{12}-c o-\mathrm{S}_{1}\right]-\mathrm{SG} 1\right)$ was synthesized as reported previously. ${ }^{30}$ In a typical experiment, a mixture of monomers (PEOMA 950 and S), SG1 and ethanol was stirred in an erlenmeyer flask and deoxygenated by nitrogen bubbling for $20 \mathrm{~min}$ at room temperature. The BlocBuilder ${ }^{\circledR}$ alkoxyamine initiator was added and nitrogen was bubbled for 10 additional min. The mixture was then introduced into a three-neck round-bottom flask $(500 \mathrm{~mL})$ and heated to $78.5^{\circ} \mathrm{C}$. The reaction was carried out for $2 \mathrm{~h}$ and the final product was dried under vacuum after precipitation in diethyl ether before analysis. Two batches with similar molar masses: $M_{\mathrm{n}}=11700$ and $12060 \mathrm{~g} \mathrm{~mol}^{-}$ 1 , but with slightly different molar mass distributions: $M_{\mathrm{w}} / M_{\mathrm{n}}=1.11$ and 1.2 , have been synthesized and used for latex particles synthesis. They will be hereafter referred to as B1 and B2, respectively.

\section{Macroalkoxyamine initiator adsorption on the silica surface. Macroalkoxyamine} solutions (batch B2) of various concentrations were mixed with a stock dispersion of the commercial Klebosol silica sol (S2 in Table 1) at $\mathrm{pH}=5.0$ to give a final macroinitiator concentration ranging from 1 to $10 \mathrm{mmol} \mathrm{L}^{-1}$ (i.e., from 0.4 to $4 \mu \mathrm{mol} \mathrm{m}{ }^{-2}$ ) while maintaining a fixed silica concentration of $50 \mathrm{~g} \mathrm{~L}^{-1}$. The dispersion was stirred for one hour, and then ultracentrifuged at $18000 \mathrm{rpm}$ for $30 \mathrm{~min}$ (Beckman Coulter Allegra 64R centrifuge). The 
carbon content in the supernatant was quantified by elemental analysis, and the density of adsorbed polymer chains, $\mathrm{A}\left(\mu \mathrm{mol} \mathrm{m} \mathrm{m}^{-2}\right)$, was determined using equation (1) as follows:

$$
\mathrm{A}\left(\mu \mathrm{mol} \mathrm{m} \mathrm{m}^{-2}\right)=\frac{[\text { Macroinitiator }]-\frac{\mathrm{C}(\%) \times 10 \times 1000}{\mathrm{~N}_{\mathrm{C}} \times 12}}{[\text { Silica }] \times \mathrm{S}_{\mathrm{spec}}} \times 10^{3}
$$

where [Macroinitiator] $\left(\mathrm{mmol} \mathrm{L}^{-1}\right)$ is the initial concentration of the macroalkoxyamine initiator, $\mathrm{C}(\mathrm{wt} \%)$ is the carbon content of the supernatant solution determined by elemental analysis, $\mathrm{N}_{C}$ is the number of carbon atoms in the macroalkoxyamine initiator $\left(\mathrm{N}_{C}=549\right)$, $S_{\text {spec. }}$ is the specific surface area of silica $\left(S_{\text {spec. }}=50 \mathrm{~m}^{2} \mathrm{~g}^{-1}\right.$, supplier data record for Klebosol colloidal silica sol) and [Silica] $\left(\mathrm{g} \mathrm{L}^{-1}\right)$ is the silica concentration.

\section{Surfactant-free emulsion polymerization of BMA and $S$ in the absence or presence of}

silica particles. In a typical surfactant-free emulsion polymerization experiment (entry EB01 in Table 2), macroinitiator (B1, $0.23 \mathrm{~g}, 1.6 \mathrm{mmol} \mathrm{L}^{-1}$ ) was dissolved in $12.5 \mathrm{~g}$ of water. The solution was then stirred under nitrogen bubbling for $30 \mathrm{~min}$ at room temperature. Then, the monomers, a mixture of BMA and $\mathrm{S}(2.35 \mathrm{~g}$ of BMA and $0.15 \mathrm{~g}$ of $\mathrm{S})$, were introduced in the aqueous solution and the obtained unstable biphasic system was deoxygenated by nitrogen bubbling for another $20 \mathrm{~min}$. This mixture was introduced into a $50 \mathrm{~mL}$ round flask, and heated at $85{ }^{\circ} \mathrm{C}$ for $6 \mathrm{~h}$. Time zero of the polymerization was taken when the reaction temperature reached $70{ }^{\circ} \mathrm{C}$. Samples were periodically withdrawn to follow the monomer conversions and molar masses. A similar procedure was used for synthesis of the multipodlike silica/polymer latex particles. In a typical experiment (entry EH01 in Table 2), macroinitiator $\left(\mathrm{B} 1,0.23 \mathrm{~g}, 1.6 \mathrm{mmol} \mathrm{L}^{-1}\right.$ ) was introduced in the silica suspension (which contained $12.5 \mathrm{~g}$ of water and $0.3125 \mathrm{~g} \mathrm{SiO}_{2}$ ). The mixture was then stirred under nitrogen bubbling for $30 \mathrm{~min}$ at room temperature and the polymerization was conducted as described 
above using a mixture of BMA and $\mathrm{S}(2.35 \mathrm{~g}$ of BMA and $0.15 \mathrm{~g}$ of $\mathrm{S})$. The size and concentration of the silica particles were varied as reported in Table 2. The natural $\mathrm{pH}$ value of the macroinitiator solutions in deionized water was close to 4.2 (due to the carboxylic acid end-groups, depending on the concentration), and was not altered for emulsion polymerization experiments performed in the absence of silica (EB01 to EB03) or in the presence of S1 and S2 (EH01 to EH06). Hydrochloric acid (0.1 M aqueous solution) was used to control the $\mathrm{pH}$ of experiments performed in the presence of S3, S4 and S5 (EH07 to EH09) before addition of the monomer.

Characterizations. The composition of the macroalkoxyamine initiator was determined by ${ }^{1}$ H NMR spectroscopy (Bruker DRX 300) by measuring the vinyl proton integrals of the monomers (three vinyl protons of $\mathrm{S}$ at $\delta=6.74 \mathrm{ppm}, \delta=5.83 \mathrm{ppm}$ and $\delta=5.25 \mathrm{ppm}$ and two $\mathrm{CH}_{2}$ protons at $\delta=6.04 \mathrm{ppm}$ and $\delta=5.69 \mathrm{ppm}$ for PEOMA) using 1,3,5-trioxane as an internal reference. ${ }^{30}$ Size exclusion chromatography (SEC) analyses were performed in THF at $40{ }^{\circ} \mathrm{C}$ for both the macroalkoxyamine initiator and the diblock copolymers obtained in the emulsion polymerization experiments. The flow rate of the mobile phase was $1 \mathrm{~mL} \mathrm{~min}^{-1}$ and toluene was used as a flow rate maker. All polymers were injected at a concentration of $3 \mathrm{mg}$ $\mathrm{mL}^{-1}$ after filtration through a $0.45 \mu \mathrm{m}$ pore-size membrane. The separation was carried out on three Polymer Laboratories columns $[3 \times$ PLgel $5 \mu \mathrm{m}$ Mixed C $(300 \times 7.5 \mathrm{~mm})]$ and a guard column (PL gel $5 \mu \mathrm{m}$ ). The average molar masses and molar mass distributions were calculated with a calibration curve based on poly (methyl methacrylate) (PMMA) standards. Samples synthesized in the presence of silica were first dried at room temperature for two days, and then diluted in THF (THF for HPLC) under stirring. The solution was then centrifuged at $21000 \mathrm{rpm}$ for $1 \mathrm{~h}$ to remove the silica particles before injection. 
Table 1. Experimental conditions and main characteristics of the silica particles used in this work.

\begin{tabular}{|c|c|c|c|c|c|c|c|c|c|c|}
\hline $\begin{array}{c}\text { Sample } \\
\text { name }\end{array}$ & $\begin{array}{l}\text { Synthetic } \\
\text { procedure }\end{array}$ & Catalyst & $\begin{array}{c}\text { [Catalyst] } \\
\left(\mathbf{m o l ~ L}^{-1}\right)\end{array}$ & $\begin{array}{l}{[\text { TEOS] }} \\
\left(\mathrm{mol} \mathrm{L}^{-1}\right)\end{array}$ & $\begin{array}{c}\text { Solids content } \\
(\%)\end{array}$ & pH & $\begin{array}{l}\mathrm{Z}_{\mathrm{av}}(\mathrm{DLS}) \\
\quad(\mathbf{n m})\end{array}$ & $\begin{array}{l}\text { Poly value } \\
\text { (DLS) }\end{array}$ & $\begin{array}{c}D_{\text {n Silica }}(\text { TEM) } \\
(\mathbf{n m})\end{array}$ & $\begin{array}{l}D_{\mathrm{w}} / D_{\mathrm{n}} \\
(\mathrm{TEM})\end{array}$ \\
\hline S1 & Hartlen & L-Arginine & $6.0 \times 10^{-3}$ & 0.717 & 3.9 & 8.9 & 43 & 0.04 & 30 & 1.01 \\
\hline S2 & Commercial silica $^{a}$ & I & l & l & 23.7 & 7.3 & 86 & 0.04 & 77 & 1.08 \\
\hline S4 & Stöber ${ }^{\mathrm{b}}$ & $\mathrm{NH}_{3}$ & 0.2 & 0.4 & 5.3 & 9.3 & 257 & 0.02 & 230 & 1.01 \\
\hline S5 & Stöber ${ }^{b}$ & $\mathrm{NH}_{3}$ & 0.3 & 0.6 & 10.0 & 9.0 & 460 & 0.06 & 440 & 1.01 \\
\hline
\end{tabular}

${ }^{a}$ Aqueous commercial silica sol (Klebosol 30N50) from Clariant (France). ${ }^{\mathrm{b}}$ The suspensions were redispersed in water through successive centrifugation/redispersion cycles before characterization.
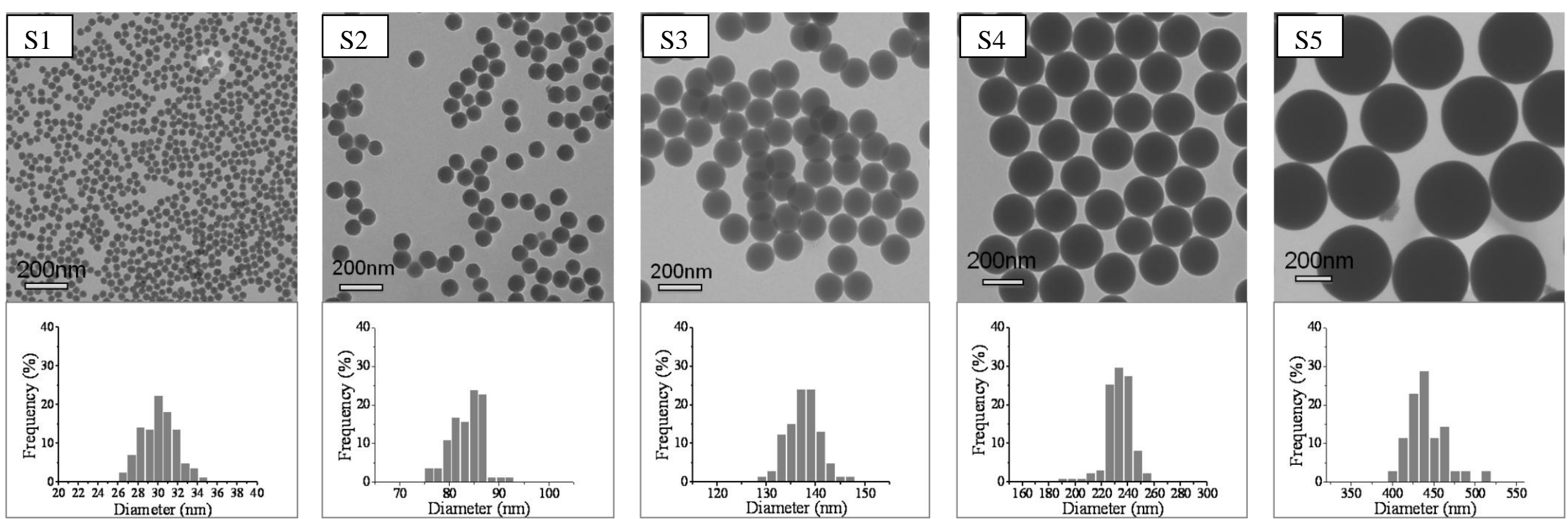

Figure 1. TEM images and size histograms of the silica particles listed in Table 1. 
Table 2. Experimental conditions and characteristics of pure $\mathrm{P}(\mathrm{BMA}-\mathrm{co}-\mathrm{S})$ latex particles and silica/polymer latex particles synthesized by surfactant-free emulsion polymerization of $n$-butyl methacrylate and styrene using the SG1-capped P[(PEOMA 950$)_{12}-$ co-S $\left._{1}\right]-\mathrm{SG} 1$ copolymer as macroinitiator in the absence and presence of silica particles of various diameters. ${ }^{\text {a }}$

\begin{tabular}{|c|c|c|c|c|c|c|c|c|c|c|c|c|}
\hline Entry & Silica & $\begin{array}{c}D_{\text {n Silica }} \\
(\mathbf{n m})^{b}\end{array}$ & $\begin{array}{c}{[\text { Silica] }} \\
\left(\mathrm{g} \mathrm{L}^{-1}\right)\end{array}$ & $\mathbf{p H}^{\mathrm{c}}$ & $\begin{array}{l}\text { [Macroinitiator] } \\
\quad\left(\mathbf{m m o l} \mathbf{L}^{-1}\right)^{\mathrm{d}}\end{array}$ & $\underset{\left(\mathrm{g} \mathrm{mol}^{-1}\right)^{\mathrm{e}}}{\operatorname{Target} M_{\mathrm{n}}}$ & $\begin{array}{l}\text { Conv. } \\
(\%)^{f}\end{array}$ & $\begin{array}{c}M_{\mathrm{n}}\left(M_{\mathrm{w}} / M_{\mathrm{n}}\right) \\
\left(\mathrm{g} \mathrm{mol}^{-1}\right)^{\mathrm{g}}\end{array}$ & $\begin{array}{c}\mathrm{Z}_{\mathrm{av}}(\mathrm{DLS}) \\
\quad(\mathbf{n m})^{\mathrm{h}}\end{array}$ & $\begin{array}{l}\text { Poly value } \\
\quad \text { (DLS) }\end{array}$ & $\begin{array}{c}D_{\text {n Latex }} \\
(\text { TEM) } \\
(\mathbf{n m}) \mathrm{i}\end{array}$ & $\begin{array}{c}D_{\mathrm{w}} / D_{\mathrm{n}} \\
(\mathrm{TEM})\end{array}$ \\
\hline EB01 & I & I & 0 & 3.9 & 1.6 & 168350 & 33.0 & $42300(2.4)$ & 301 & 0.14 & 181 & 1.03 \\
\hline EB03 & I & I & 0 & 4.0 & 6.9 & 40000 & 70.1 & $29320(1.6)$ & 80 & 0.05 & 50 & 1.04 \\
\hline EH01 & S1 & 30 & 25 & 5.0 & 1.6 & 141176 & 35.3 & $24000(2.3)$ & 154 & 0.24 & 60 & 1.03 \\
\hline ЕH02 & S1 & 30 & 22 & 5.4 & 3.2 & 72606 & 75.7 & $39900(1.7)$ & 136 & 0.13 & 64 & 1.04 \\
\hline EH04 & S2 & 77 & 50 & 5.5 & 1.6 & 146290 & 30.0 & $53200(1.7)$ & 245 & 0.52 & 96 & 1.08 \\
\hline EH05 & S2 & 77 & 50 & 6.0 & 3.2 & 80180 & 74.4 & $33000(1.7)$ & 219 & 0.12 & 88 & 1.06 \\
\hline EH06 & S2 & 77 & 50 & 5.7 & 6.9 & 39920 & 71.0 & $27780(1.5)$ & 270 & 0.53 & 57 & 1.07 \\
\hline EH07 & S3 & 136 & 50 & $5.8(+)$ & 3.2 & 80015 & 52.8 & $57300(1.8)$ & 218 & 0.57 & 86 & 1.03 \\
\hline EH08 & S4 & 230 & 50 & $5.7(+)$ & 3.2 & 80235 & 50.5 & $27500(2.2)$ & 167 & 0.28 & 85 & 1.06 \\
\hline
\end{tabular}

${ }^{a}$ All polymerizations were carried out at $85^{\circ} \mathrm{C}$ for $6 \mathrm{~h}$. The total monomer concentration was $20 \mathrm{wt} \%$ and the initial molar fraction of styrene was $f_{\mathrm{S} 0}=0.08$.

${ }^{\mathrm{b}}$ Determined by TEM (see Table 1). ${ }^{\mathrm{c}}$ Initial $\mathrm{pH}$ determined before polymerization, natural or adjusted with $\mathrm{HCl}(+)$. ${ }^{\mathrm{d}}$ All polymerizations were conducted using B1 as macroalkoxyamine initiator except runs EB03, EH03, EH04 and EH06 that were performed using B2. ${ }^{\mathrm{e}}$ Theoretical molar mass at $100 \%$ conversion determined according to: Target $M_{\mathrm{n}}\left(\mathrm{g} \mathrm{mol}^{-1}\right)=M_{\mathrm{n}}{ }^{\text {alkoxyamine }}+\left(\frac{\text { initial mass of monomer }}{\text { initial mass of alkoxyamine }}\right) \times M_{\mathrm{n}}{ }^{\text {alkoxyamine }} \cdot{ }^{\mathrm{f}}$ Determined by gravimetric analysis. ${ }^{\mathrm{g}}$ Determined by SEC in THF with PMMA standards. ${ }^{\mathrm{h}}$ Hydrodynamic diameter of the pure polymer or hybrid latex particles. ${ }^{\mathrm{i}}$ Diameter of the polymer nodules determined by TEM. 
Dynamic light scattering (DLS, Nano ZS from Malvern Instruments) was used to measure the particle size (average hydrodynamic diameter, $\mathrm{Z}_{\mathrm{av}}$ ) and the dispersity of the samples (indicated by the poly value - the higher this value, the broader the size distribution). Before measurements, the samples were diluted in deionized water. The silica particles were imaged by transmission electron microscopy (TEM) with a Philips CM120 transmission electron microscope operating at an accelerating voltage of $80 \mathrm{kV}$ (Centre Technologique des Microstructures, platform of the Université Claude Bernard, Lyon 1). Highly diluted samples were dropped on a formvar-carbon coated copper grid and dried under air. To prevent particles deformation (the $\mathrm{P}(\mathrm{BMA}-\mathrm{co}-\mathrm{S})$ hydrophobic block constituting the core of the latex particles has a glass transition temperature, $\mathrm{T}_{\mathrm{g}}$, close to the ambient), and allow reliable determination of particles size and morphology, the pure polymer and hybrid latex particles were characterized by cryo-transmission electron microscopy (cryo-TEM). As described in details elsewhere, ${ }^{62}$ thin liquid films of $0.1 \mathrm{wt} \%$ suspensions were formed onto commercial "lacey" carbon membranes (Pelco, USA) and vitrified by quench freezing into liquefied ethane. The grids were then mounted in a Gatan 626 specimen holder, precooled with liquid nitrogen, and subsequently observed at $-180{ }^{\circ} \mathrm{C}$, under low dose illumination, using a Philips CM200 Cryo microscope operating at $80 \mathrm{kV}$. The number-average $\left(D_{\mathrm{n}}\right)$ and the weightaverage $\left(D_{\mathrm{w}}\right)$ diameters of the silica particles, of the polymer latex particles (for experiments performed in the absence of silica) and of the polymer nodules (for experiments performed in the presence of silica), were determined directly on the TEM micrographs according to: $D_{\mathrm{n}}=$ $\Sigma \mathrm{n}_{\mathrm{i}} D_{\mathrm{i}} / \Sigma \mathrm{n}_{\mathrm{i}}$ and $D_{\mathrm{w}}=\Sigma \mathrm{n}_{\mathrm{i}} D_{\mathrm{i}}{ }^{4} / \Sigma \mathrm{n}_{\mathrm{i}} D_{\mathrm{i}}{ }^{3}$, where $\mathrm{n}_{\mathrm{i}}$ is the number of particles with diameter $D_{\mathrm{i}}$. A minimum of 150 particles was counted for each batch. The number ratio of polymer latex particles to silica particles, $\mathrm{N}_{\text {Latex }} / \mathrm{N}_{\text {Silica }}$, was determined by two methods. The first method was based on statistical analysis of the cryo-TEM images by counting manually the number of latex particles and the number of silica particles and making the ratio. In most cases, silica and 
polymer particles showed significantly different contrasts and could be thus unambiguously identified on the micrographs. In the second method, $\mathrm{N}_{\text {Latex }} / \mathrm{N}_{\text {Silica }}$, was determined according to the equation (2) below:

$$
\frac{\mathrm{N}_{\text {Latex }}}{\mathrm{N}_{\text {Silica }}}=\frac{[\text { Polymer }]}{[\text { Silica }]}\left(\frac{\mathrm{d}_{\text {Silica }}}{\mathrm{d}_{\text {Polymer }}}\right)\left(\frac{D_{\mathrm{n} \text { Silica }}}{D_{\mathrm{n} \text { Latex }}}\right)^{3} \quad \text { (eq. 2) }
$$

where [Silica] $\left(\mathrm{g} \mathrm{L}^{-1}\right)$ is the silica concentration, [Polymer] $\left(\mathrm{g} \mathrm{L}^{-1}\right)$ is the polymer concentration determined by gravimetry, $\mathrm{d}_{\text {Silica }}$ and $\mathrm{d}_{\text {Polymer }}\left(\mathrm{g} \mathrm{cm}^{-3}\right)$ are the silica and polymer mass densities, respectively, and $D_{\mathrm{n} \text { Silica }}$ and $D_{\mathrm{n} \text { Latex }}(\mathrm{nm})$ are the diameters of the silica and latex particles determined by cryo-TEM, respectively.

Cryo-scanning electron microscopy (cryo-SEM) was performed in a FEI QUANTA 250 FEG scanning electron microscope, at an acceleration voltage of $15 \mathrm{kV}$. The specimen was first mounted on an appropriate holder, which was itself mounted onto a freezing/vacuum transfer rod. The sample was plunge-frozen in slushy nitrogen and then transferred under vacuum in the cooled stage of the cryo-SEM preparation chamber. The preparation chamber was pumped by a rotary pump. Finally the gate valve between the preparation chamber and the SEM was raised, and the specimen transferred in the cooled stage of the SEM before observation.

\section{RESULTS AND DISCUSSION}

\section{Synthesis of highly monodisperse silica particles}

Recent studies from our group on the synthesis of multipod-like silica/polystyrene particles through conventional emulsion polymerization, have emphasized the importance of controlling the size and size distribution of the silica seed particles in order to get well-defined 
polymer/silica clusters with uniform morphologies. ${ }^{19,22}$ The synthesis of monodisperse silica particles is extensively documented in the literature. ${ }^{63}$ Silica spheres with controlled size and size distributions can now be synthesized using a variety of experimental conditions. In order to get monodisperse silica particle over a large size range, we used three complementary approaches. Very small silica particles of $30 \mathrm{~nm}$ were first obtained following the protocol of Hartlen et $a l .{ }^{56}$ known to produce highly monodisperse silica nanoparticles ( $\mathrm{S} 1$, Table 1). These particles were then used as seeds to generate silica particles with a diameter of $136 \mathrm{~nm}$ (S3, Table 1) whereas larger silica particles were synthesized using the conventional Stöber process $^{61}$ (S4 and S5, Table 1). In addition, a commercial Klebosol silica sol $\left(D_{\mathrm{n}}=77 \mathrm{~nm}, \mathrm{~S} 2\right.$, Table 1) was also used to complete the series. Figure 1 shows the TEM images and size histograms of the silica particles used in this work. Their diameters are comprised between 30 and $440 \mathrm{~nm}$ (as determined by TEM) and their size distribution is very narrow $\left(D_{\mathrm{w}} / D_{\mathrm{n}}\right.$ typically lower than 1.01$)$ with the exception of the commercial silica sol $\left(D_{\mathrm{w}} / D_{\mathrm{n}}=1.08\right)$. As the latter was available in larger quantities, it was selected to study macroinitiator adsorption described in the following section.

\section{Macroalkoxyamine adsorption on the silica surface}

Studying the adsorption of the PEO-based macroalkoxyamine on the silica surface is of primary importance to understand the mechanism of subsequent hybrid particle formation. The adsorbed amounts were determined by elemental analysis using equation (1). The carbon contents of the supernatant solutions and the free macroalkoxyamine concentrations are reported in the Supporting Information (Table S1). Figure 2 shows the isotherm for adsorption of the P[(PEOMA $\left.\left.{ }_{950}\right)_{12}-c o-S_{1}\right]-S G 1$ macroalkoxyamine onto the silica sol (S2, Table 1) at a fixed concentration of $50 \mathrm{~g} \mathrm{~L}^{-1}$ and $\mathrm{pH}=5.0$. 


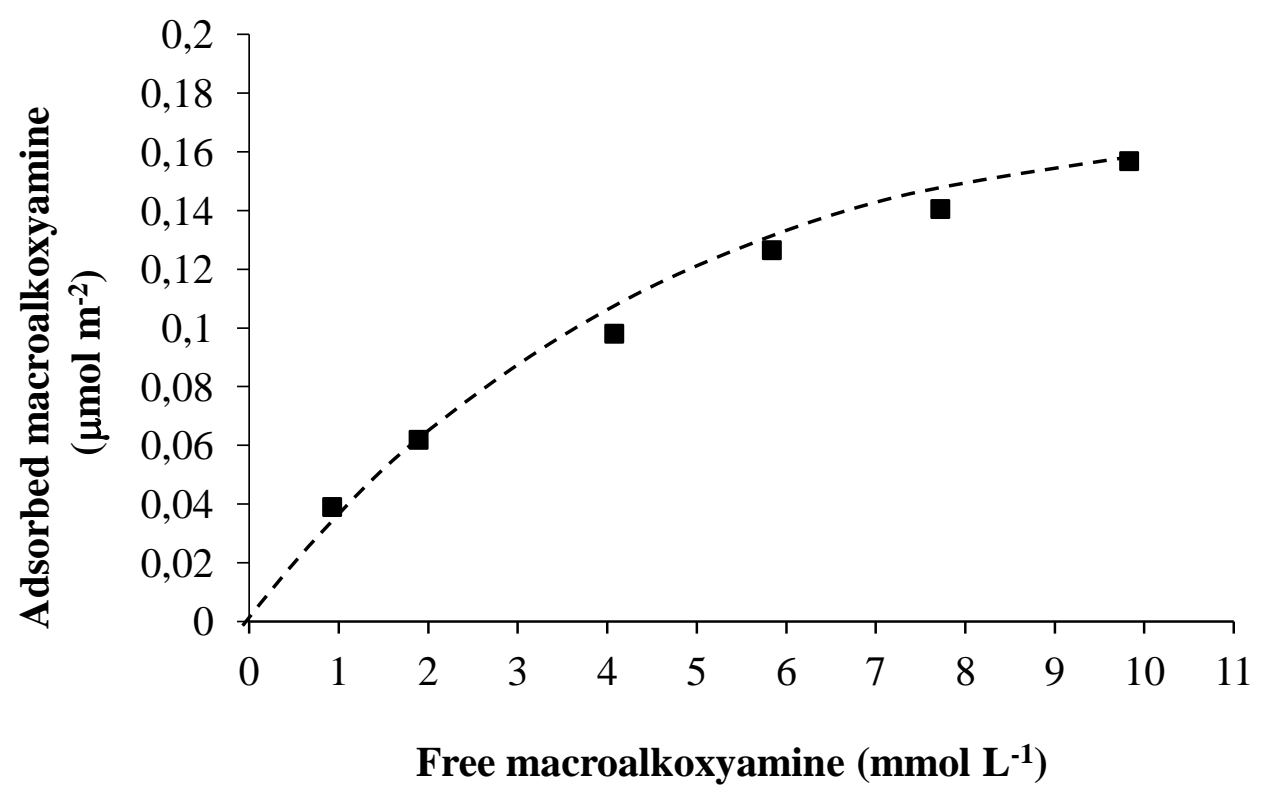

Figure 2. Adsorption isotherm of the $\mathrm{P}\left[\left(\mathrm{PEOMA}_{950}\right)_{12}-c o-\mathrm{S}_{1}\right]-\mathrm{SG} 1$ macroalkoxyamine initiator onto the Klebosol silica sol $(\mathrm{S} 2$, Table 1$)$ at $25^{\circ} \mathrm{C}$ and $\mathrm{pH}=5.3$. [Silica] $=50 \mathrm{~g} \mathrm{~L}^{-1}$.

The adsorbed amount of macroalkoxyamine on the silica surface increases as the macroinitiator concentration increases, until a pseudo-plateau is reached for a concentration close to $10 \mathrm{mmol} \mathrm{L}^{-1}$, which corresponds to a maximal adsorption capacity of around 0.16 $\mu \mathrm{mol} \mathrm{m} \mathrm{m}^{-2}$ (i.e. $1.87 \mathrm{mg} \mathrm{m}^{-2}$ ). The macroinitiator partitions between the silica surface and the aqueous phase, and at most $10 \mathrm{~mol} \%$ of the total introduced macroinitiator was adsorbed at the silica surface, with the rest remaining free in solution.

Several researchers have studied the adsorption of PEO-based polymers on silica surfaces. ${ }^{64-71}$ It has been reported that brush-type polymers with PEO side chains (also known as comb polymers) adsorb more than their linear counterparts. Adsorption takes place through the side chains and involves the formation of hydrogen bonds between surface silanols and hydrogen atoms on the polymer. ${ }^{64-65}$ Densely-grafted comb-like polymers are known to adopt a stiff rod-like conformation in dilute solutions, with the stiff nature of the polymer originating from the repulsions between PEO side chains. ${ }^{70}$ It is expected that this conformation is largely 
retained when the polymer adsorbs onto a surface. Indeed, simulations predict that comb-like polymers adopt a flat conformation at the interface to maximize the interaction between PEO and the surface silanol groups. This results in the formation of thin adsorbed layers, and hence in a large occupied area per chain. ${ }^{70}$ Although many of the PEO side chains interact with the surface, some of them must be extended into solution for geometrical reasons as represented in Scheme 1. Our results are in good agreement with these assumptions. Indeed the adsorbed amount at saturation (i.e. $1.87 \mathrm{mg} \mathrm{m}^{-2}$ ) is higher than that reported for high molar mass linear PEO (i.e. around $\left.0.4-0.8 \mathrm{mg} \mathrm{m}^{-2}\right)^{64-66}$ and is consistent with literature values for the adsorption of PEO brush-like polymers whose structures are similar to that of our macroalkoxyamine initiator. ${ }^{67,69,71}$ For instance, Naderi et al. ${ }^{69}$ studied the adsorption of $\mathrm{P}\left(\mathrm{PEOMA}_{2000}\right)$ comb-like polymers with a molar mass of $4 \times 10^{5} \mathrm{~g} \mathrm{~mol}^{-1}$ onto silica and found a maximum adsorbed amount of $1.17 \mathrm{mg} \mathrm{m}^{-2}$, a value in good agreement with ours. The maximum adsorbed amount of $1.87 \mathrm{mg} \mathrm{m}^{-2}$ corresponds to an area of $10 \mathrm{~nm}^{2}$ per adsorbed macroinitiator molecules, which is also in agreement with previous literature reports.

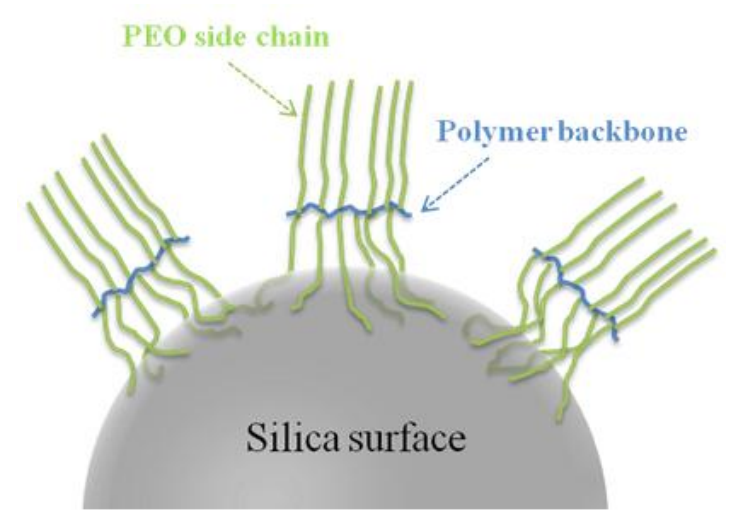

Scheme 1. Scheme for adsorption of the brush-like $\mathrm{P}\left[\left(\mathrm{PEOMA}_{950}\right)_{12}-\mathrm{co}-\mathrm{S}_{1}\right]-\mathrm{SG} 1$ macroalkoxyamine initiator on the silica surface. 


\section{Synthesis of silica/polymer hybrid particles}

In the following, we took advantage of the successful adsorption of the macroalkoxyamine initiator onto silica to synthesize silica/polymer hybrid particles using NMP in aqueous dispersed media. The role of the living polymer in the system was threefold: a compatibilizer, an initiator, and a stabilizer, thus avoiding the need for any external molecular surfactant or radical initiator. We systematically investigated the effect of macroinitiator concentration and particle size on the polymerization kinetics and control, and on the stability and structure of the self-assembled nano-objects (Table 2). Firstly, different macroinitiator concentrations were tested using two different silica particle sizes $(30 \mathrm{~nm}$ and $77 \mathrm{~nm})$, and secondly the silica particle size was varied at a fixed macroinitiator concentration of $3.2 \mathrm{mM}$.

\subsection{Effect of macroinitiator concentration}

\subsubsection{Kinetics}

The effect of the macroinitiator concentration on kinetics was studied for the $30 \mathrm{~nm}$ and 77 $\mathrm{nm}$ silica particles ( $\mathrm{S} 1$ and $\mathrm{S} 2$, respectively, Table 1), using 1.6, 3.2 or $6.9 \mathrm{mmol} \mathrm{L}^{-1}$ of macroinitiator (EH01 to EH06, Table 2). The $\mathrm{pH}$ of the macroinitiator/silica mixture was around 5 and there was no $\mathrm{pH}$ adjustment needed for these samples. The polymerization kinetics, shown in Figure 3 in the case of the $30 \mathrm{~nm}$ silica particles, exhibits a trend similar to that previously observed for the blank emulsion polymerization performed in the absence of silica particles under similar conditions. ${ }^{30}$ Conversions are limited to c.a. $70 \%$ and the higher the concentration of macroinitiator, the higher is the polymerization rate. Similar results were obtained for the $77 \mathrm{~nm}$ silica particles. Limited conversions have often been reported for 
nitroxide-mediated emulsion polymerization of MMA using macroinitiators based on styrene as a comonomer. ${ }^{28 a}$ They are first an intrinsic outcome of NMP, which is based on the persistent radical effect that leads to an accumulation of SG1 due to continuous irreversible termination reactions of the propagating radicals. The situation is moreover enhanced for the polymerization of methacrylic esters in the presence of styrene because the proportion of styrene in the polymerization medium is very low and continuously decreases. Such decrease is related to the reactivity ratios and to the low initial amount of this comonomer. The fact that the final conversion increases with increasing macroinitiator concentration is also related to the persistent radical effect and to the proportion of released SG1, which is expected to be smaller when the initial alkoxyamine concentration is increased, hence leading to a higher concentration of propagating radicals. $^{72}$

Figure 4 and Figure 5 show the evolution of the SEC chromatograms and of the molar mass and molar mass dispersity with conversion, respectively, again for the $30 \mathrm{~nm}$ silica particles. The shift of the chromatograms towards higher conversions reveals the living character of the polymerization. In addition, the shape of the SEC traces is similar to the one reported in our previous work in the absence of silica and indicates the presence of a small proportion of dead chains. As seen in Figure 5 the control over the chain growth is improved (better match between the experimental values and the theoretical ones, lower molar mass dispersities and higher reinitiation efficiency) when the initial concentration was increased, which is again consistent with our previous observations. 


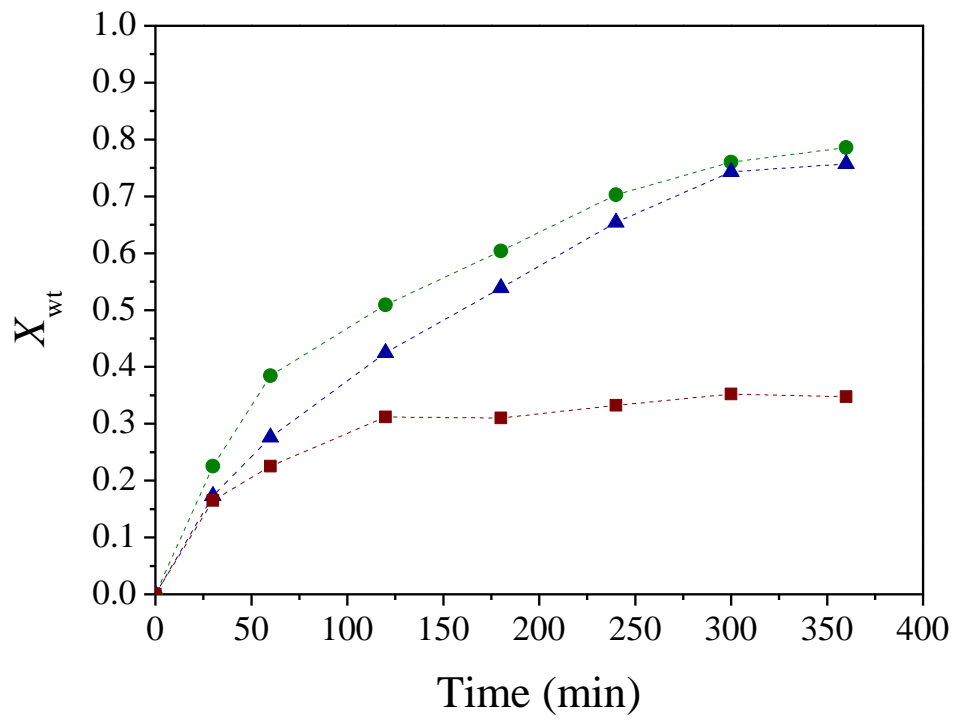

Figure 3. Evolution of monomer conversion with time during the surfactant-free emulsion polymerization of BMA with $\mathrm{S}$ in the presence of $30 \mathrm{~nm}$ diameter silica particles (S1, [Silica] $\left.=25 \mathrm{~g} \mathrm{~L}^{-1}\right)$ for three different macroinitiator concentrations. EH01 (B1, $1.6 \mathrm{mmol} \mathrm{L}^{-1}$, red $\left.\mathbf{m}\right)$, EH02 (B1, $3.2 \mathrm{mmol} \mathrm{L}^{-1}$, blue $\left.\mathbf{\Delta}\right)$ and EH03 (B2, $6.9 \mathrm{mmol} \mathrm{L}^{-1}$, green •) (Table 2).

However, for a given macroinitiator concentration, the quality of control was overall poorer than in the absence of silica particles. ${ }^{30}$ This is likely due to the higher ionic strength of the suspension. Indeed, we showed in our previous work that an increase of ionic strength induced a loss of control. ${ }^{30}$ In the present system, the increase of ionic strength can be predominantly attributed to the silica's compensating counter-ions and to the L-arginine used as catalyst during silica synthesis. 

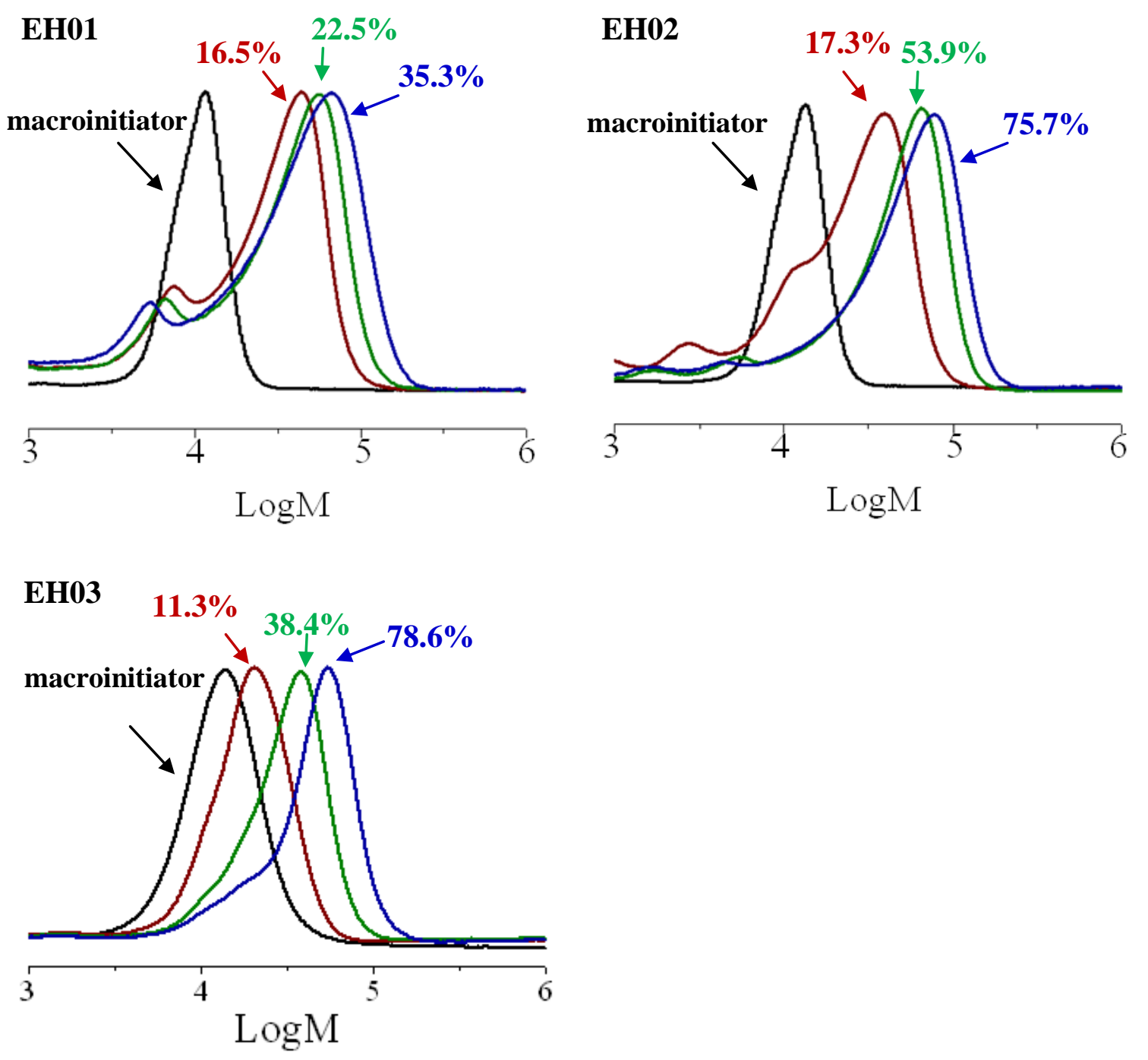

Figure 4. Evolution of the size exclusion chromatograms with weight conversion during the surfactant-free emulsion copolymerization of BMA and $\mathrm{S}$ in the presence of $30 \mathrm{~nm}$ diameter silica particles (S1) and for three different macroinitiator concentrations. EH01 (B1, 1.6 mmol $\left.\mathrm{L}^{-1}\right)$, EH02 (B1, $\left.3.2 \mathrm{mmol} \mathrm{L}^{-1}\right)$ and EH03 (B2, $\left.6.9 \mathrm{mmol} \mathrm{L}^{-1}\right)$ (Table 2). 


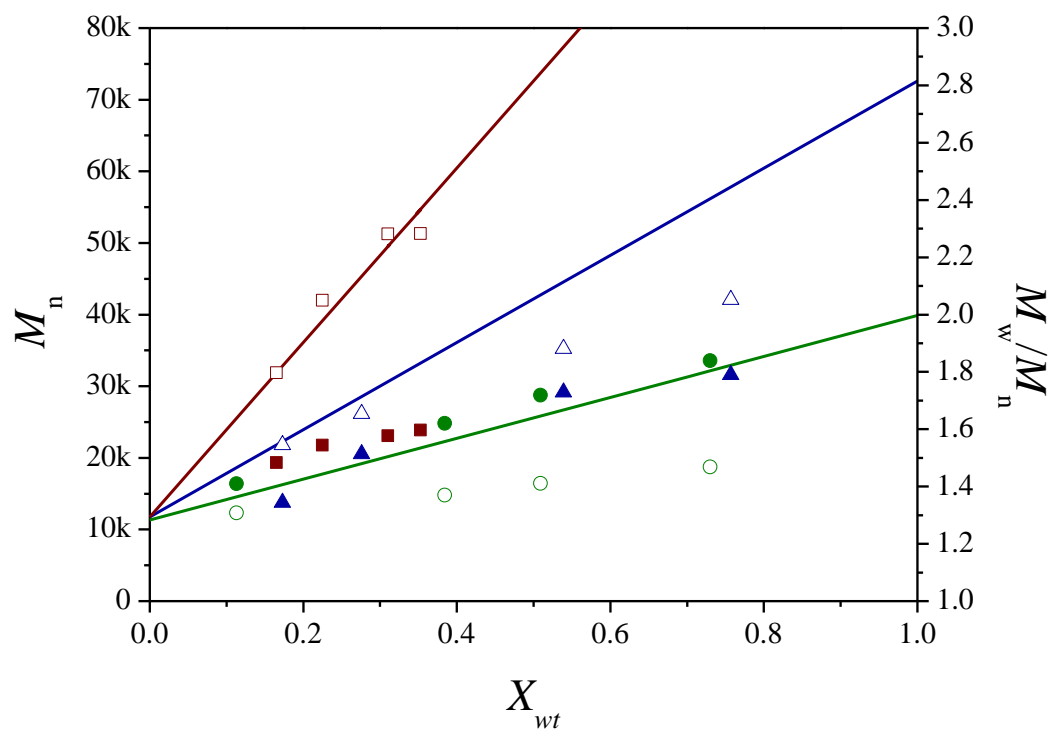

Figure 5. Evolution of $M_{\mathrm{n}}$ and $M_{\mathrm{w}} / M_{\mathrm{n}} v s$ weight conversion (the full lines represent the theoretical $M_{\mathrm{n}}$ ) for the surfactant-free emulsion copolymerizations of BMA and $\mathrm{S}$ in the presence of $30 \mathrm{~nm}$ diameter silica particles (S1) for three different macroinitiator concentrations. EH01 (B1, $1.6 \mathrm{mmol} \mathrm{L}{ }^{-1}, M_{\mathrm{n}}$, red $\mathbf{m} ; M_{\mathrm{w}} / M_{\mathrm{n}}$, red $\left.\square\right)$, EH02 (B1, $3.2 \mathrm{mmol} \mathrm{L}{ }^{-1}$, $M_{\mathrm{n}}$, blue $\boldsymbol{\Delta} ; M_{\mathrm{w}} / M_{\mathrm{n}}$ blue $\left.\triangle\right)$ and EH03 $\left(\mathrm{B} 2,6.9 \mathrm{mmol} \mathrm{L} \mathrm{L}^{-1}, M_{\mathrm{n}}\right.$, green $\bullet, M_{\mathrm{w}} / M_{\mathrm{n}}$, green $\left.\odot\right)$ (Table 2).

\subsubsection{Particle morphology}

The hybrid particles synthesized in the presence of $30 \mathrm{~nm}$ diameter silica particles $\left(25 \mathrm{~g} \mathrm{~L}^{-1}\right)$ and the lowest macroinitiator concentration (EH01, $\left.1.6 \mathrm{mmol} \mathrm{L}^{-1}\right)$, were characterized by cryo-TEM (Figure 6). The latex particles showed significant affinity for the silica spheres as almost each polymer nodule (in light grey) was in contact with at least one silica particle (in dark grey). Isolated silica beads and free latex particles could also be occasionally seen, together with a few trimers (i.e. two polymer nodules having grown from each side of one silica particle) and hybrid structures resulting from the growth of one latex particle on strings of two of three silica beads. A statistical calculation of the respective number of polymer nodules and silica particles by manually counting the number of latex particles and the 
number of silica particles led to a ratio close to 1 . The same analysis performed for higher macroinitiator concentrations (EH02, $3.2 \mathrm{mmol} \mathrm{L}^{-1}$ and $\mathrm{EH} 03,6.9 \mathrm{mmol} \mathrm{L}^{-1}$, Figure 6) led to on average 3 and 5.8 polymer nodules per silica particle, respectively, which is in agreement with the observed TEM morphologies, which evolved from dimers (one polymer nodule per silica particle), to tripods (3 latex per silica) and finally daisy-like hybrids (each silica sphere being surrounded by more than three polymer nodules). Using equation (2) (setting $\mathrm{d}_{\text {Silica }}$ to $2.1 \mathrm{~g} \mathrm{~cm}^{-3}$ and $\mathrm{d}_{\text {Polymer }}$ to $1.0 \mathrm{~g} \mathrm{~cm}^{-3}$ ) and the silica and latex particle diameters determined by TEM, we found $\mathrm{N}_{\text {Latex }} / \mathrm{N}_{\text {Silica }}$ ratios of $0.7,1.5$ and 3.2 for EH01, EH02 and EH03, respectively (Table 3). These values are in reasonable agreement with those obtained by manual counting although they are slightly smaller. The observed difference may be due to the presence of a solvated hairy layer around the polymer particles that would lead to an overestimation of the latex particle size and hence to an under-estimation of the polymer particles number.
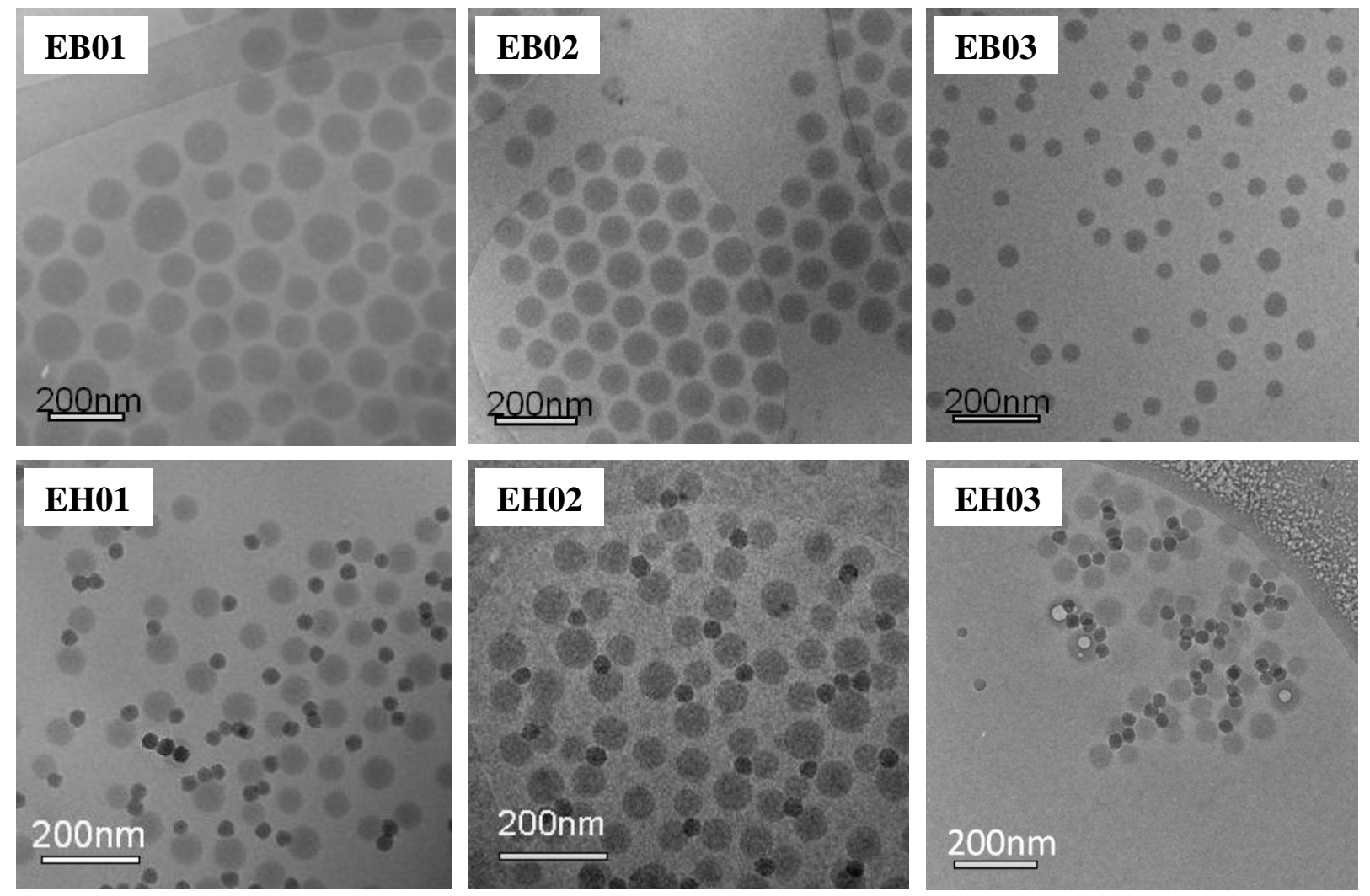
Figure 6. Cryo-TEM images of the final pure polymer latex particles (EB01, EB02 and EB03) and multipod-like silica/polymer latex particles (EH01, EH02 and EH03) obtained by surfactant-free emulsion copolymerization of BMA and $\mathrm{S}$ in the absence and in the presence of $30 \mathrm{~nm}$ diameter silica particles $\left(\mathrm{S} 1\right.$, $[$ Silica $\left.]=25 \mathrm{~g} \mathrm{~L}^{-1}\right)$ for three different $\mathrm{P}\left[\left(\mathrm{PEOMA}_{950}\right)_{12^{-}}\right.$ $\left.c o-\mathrm{S}_{1}\right]-\mathrm{SG} 1$ macroinitiator concentrations. EB01, EH01 (B1, $\left.1.6 \mathrm{mmol} \mathrm{L}^{-1}\right), \mathrm{EB} 02, \mathrm{EH} 02$ (B1, $\left.3.2 \mathrm{mmol} \mathrm{L}^{-1}\right)$ and EB03, EH03 (B2, $\left.6.9 \mathrm{mmol} \mathrm{L}^{-1}\right)$ (Table 2).

Figure 7 shows the morphology of the hybrid particles obtained with $77 \mathrm{~nm}$ silica particles (S2, Table 1) for increasing macroalkoxyamine concentrations. Similarly to the experiments performed with the $30 \mathrm{~nm}$ silica particles, the morphology evolved from dumbbell- to daisyshaped when the macroinitiator concentration increased from 1.6 to 3.2 and then $6.9 \mathrm{mmol} \mathrm{L}^{-}$ ${ }^{1}$. For the lowest concentration (EH04, Table 2), the formation of dumbbell-like particles with an average of 1.3 polymer nodules per silica seed was favoured. Those nodules have an average diameter of $96 \mathrm{~nm}$ as determined by TEM (Table 3). An estimation of $\mathrm{N}_{\text {Latex }} / \mathrm{N}_{\text {Silica }}$ by counting on the TEM micrograph the number of latex and silica particles led to a ratio of 1.2. For higher macroalkoxyamine concentrations (i.e. EH05 and EH06), each silica particle was surrounded by in average 5 to 6 latex particles. Calculation of $\mathrm{N}_{\text {Latex }} / \mathrm{N}_{\text {Silica }}$ based on equation (2) gave a ratio of 4.2 and 14.7 respectively (Table 3 ). The discrepancy between both series of measurements is most likely due to difficulties in precise determination of the number of polymer nodules located at the silica surface by manual counting. Indeed, in case of sample EH05, most of the latex particles seem to be located in the equatorial plane of the silica spheres which allows satisfactory estimation of the $\mathrm{N}_{\text {Latex }} / \mathrm{N}_{\text {Silica }}$ ratio. If there was one latex particle above the silica particles, one should be able to distinguish it as the diameter of the latex particles (i.e. around $88 \mathrm{~nm}$ ) is larger than the silica particle size (i.e. $77 \mathrm{~nm}$ ). However, when the macroinitiator concentration was increased further to $6.9 \mathrm{mmol} \mathrm{L}^{-1}$ (EH06), the latex 
particle size decreased from 88 to $57 \mathrm{~nm}$ leading to an increase of the particle number in agreement with in situ formation of amphiphilic block copolymer self-assemblies (Table 3). As the size of the latex particles was smaller than that of the silica sphere, they could not be easily identified on the TEM grid which rendered the determination of the $\mathrm{N}_{\text {Latex }} / \mathrm{N}_{\text {Silica }}$ ratio less accurate. Besides, as the number of latex particles was higher than the theoretical number that could be close packed (with hexagonal symmetry) on each silica sphere, ${ }^{73}$ "free" latex particles with no apparent interaction with the silica surface were also formed concurrently to the multipod-like particles. Those free latex particles also contributed to increasing the $\mathrm{N}_{\text {Latex }} / \mathrm{N}_{\text {Silica }}$ ratio.

Planar arrangements similar to the ones observed for the intermediate macroinitiator concentration have already been reported during the synthesis of silica/polystyrene particles through seeded emulsion polymerization using PEOMA- $^{19}$ or methacryloxy methyl triethoxysilane-functionalized silica particles as seeds. ${ }^{17,18}$ These $2 \mathrm{D}$ arrangements were attributed to the collapse of the PS nodules during TEM observation which was carried out in a conventional microscope at room temperature. Indeed, imaging the same samples by cryoTEM and cryo-electron tomography revealed that the arrangement of the biphasic particles in suspension was not planar, but in polyhedral shapes such as square antiprisms. ${ }^{75}$ In the present study, we also used cryo-TEM to prevent particle deformation and visualize the particles in their original shape, and therefore did not expect to observe such a planar morphology. However, the possibility of mechanical deformations during sample preparation cannot be entirely ruled out, and three-dimensional tomographic reconstructions similar to those mentioned above would therefore be very helpful to assess the exact morphology of the observed daisy structure. 

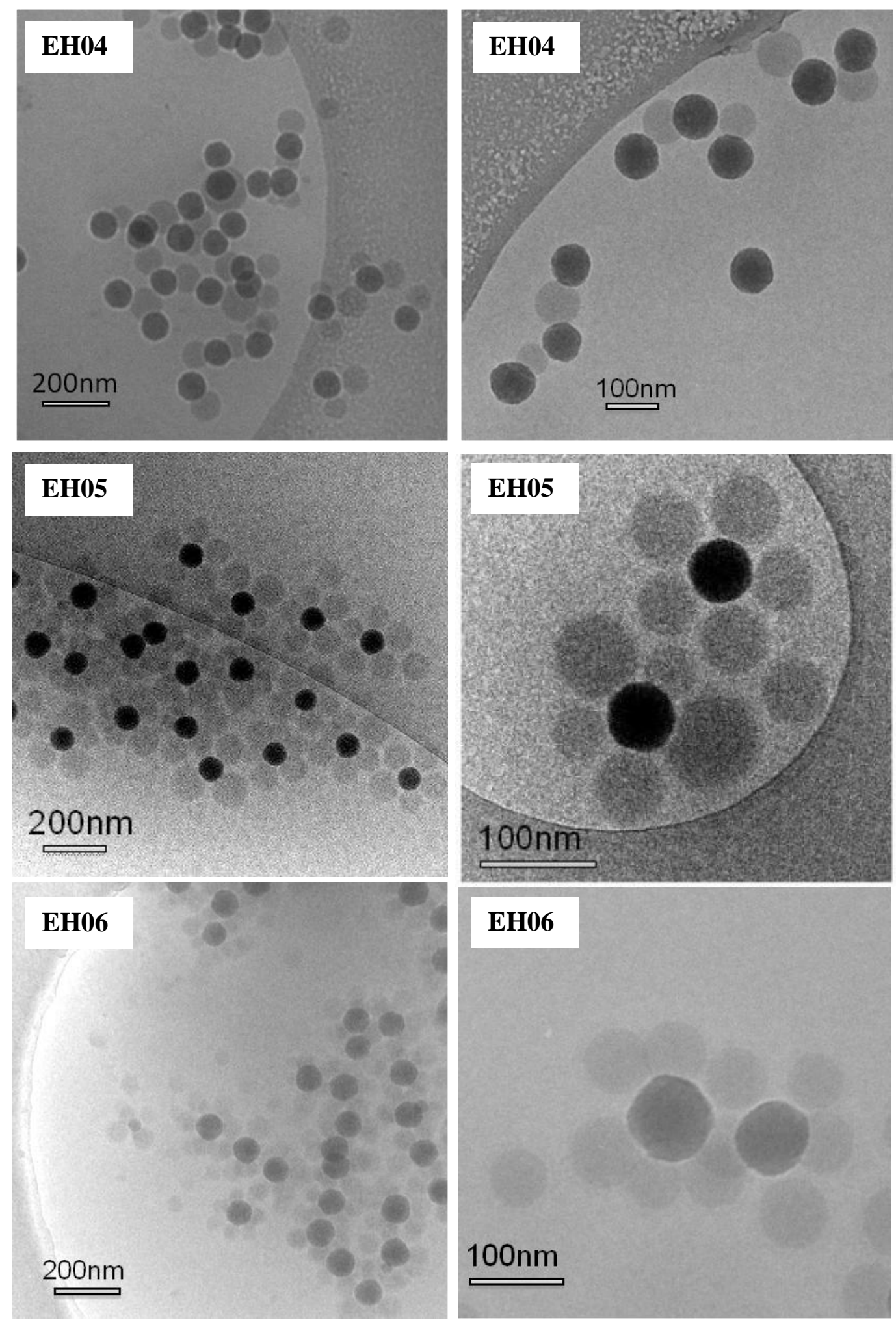

Figure 7. Cryo-TEM images of the final multipod-like silica/polymer latex particles obtained by surfactant-free emulsion copolymerization of BMA and $\mathrm{S}$ in the presence of $77 \mathrm{~nm}$ silica (S2 in Table 1) for different $\mathrm{P}\left[\left(\mathrm{PEOMA}_{950}\right)_{12}-\mathrm{co}-\mathrm{S}_{1}\right]-\mathrm{SG} 1$ concentrations (EH04, B2, 1.6 mmol L $\left.{ }^{-1}\right)$, EH05 (B1, $\left.3.2 \mathrm{mmol} \mathrm{L}^{-1}\right)$ and EH06 (B2, $\left.6.9 \mathrm{mmol} \mathrm{L}^{-1}\right)($ Table 2). 
In order to gain further insight into the mechanism of hybrid particles formation, we have compared in Table 3 the diameters and numbers of latex particles synthesized in the absence and presence of silica under otherwise identical experimental conditions (i.e. same macroinitiator and monomer concentrations). The particle size is clearly smaller and the particle number larger when the emulsion polymerization was carried out in the presence of silica particles. This is particularly evident for the $30 \mathrm{~nm}$ silica particles using the lowest macroalkoxyamine concentration $\left(\mathrm{EH} 01,1.6 \mathrm{mmol} \mathrm{L}^{-1}\right.$ ) but it also holds true for the $77 \mathrm{~nm}$ silica particles (EH04) under similar conditions. In this last case, the adsorption isotherm showed the presence of a significant amount of free macroinitiator in the aqueous phase irrespective of the initial macroalcoxyamine concentration. Accordingly, the polymerization likely starts both in water and on the silica surface as depicted in Scheme 2. The resulting block copolymers would then self-assemble in water to form free polymer latex particles or self-assemble with the ones generated at the silica surface to form surface-adsorbed polymer nodules. However, the low fraction of free latex particles suggests that they prefer to selfassemble with the ones formed at the silica surface in order to minimize interfacial free energy and increase colloidal stability. Furthermore, the fact that the latex particle size strongly decreases in the presence of silica for the lowest macroinitiator concentration (Table 3) suggests that the silica particles also contribute to the stabilization of the self-assembled block copolymers. Indeed, for the lowest macroinitiator concentration, the surface coverage is low and the remaining dissociated exposed silanol groups of silica can provide extra colloidal stability to the growing polymer spheres resulting in smaller particle sizes. Indeed calculation gives only $30 \%$ coverage at $1.6 \mathrm{mmol} \mathrm{L}^{-1}$, which corresponds to an area per adsorbed molecule of $30 \mathrm{~nm}^{2}$ (compared to $10 \mathrm{~nm}^{2}$ for full coverage). Among the specificities of this new surface PISA process is thus the possibility to tune the latex particle size, and hence the 
final morphology, by simply varying the macroinitiator concentration and the surface coverage.

Table 3. Respective diameters and numbers of latex particles, silica spheres and polymer nodules, and corresponding latex-to-silica number ratios during the synthesis of pure polymer and silica/polymer hybrid particles by NMP-mediated emulsion polymerization.

\begin{tabular}{|c|c|c|c|c|c|c|c|c|}
\hline Entry & $\begin{array}{c}\text { [Macroinitiator] } \\
\left.(\mathbf{m m o l ~ L})^{-1}\right)\end{array}$ & $\begin{array}{c}D_{\text {n Silica }} \\
(\mathbf{n m})\end{array}$ & $\begin{array}{r}N_{\text {Silica }} \\
\times 10^{17} L^{-1} \\
\end{array}$ & $\begin{array}{c}D_{\text {n Latex }} \\
(\mathbf{n m})\end{array}$ & $\begin{array}{r}\mathbf{N}_{\text {Latex }} \\
\times 10^{17} L^{-1} \\
\end{array}$ & $\begin{array}{l}\mathbf{N}_{\text {Latex }} / \\
\mathbf{N}_{\text {Silica }}{ }^{a}\end{array}$ & $\begin{array}{l}D_{\text {n Silical }} \\
D_{\text {n Latex }}\end{array}$ & $\mathbf{N}_{\max }$ \\
\hline EB01 & 1.6 & I & I & 181 & 0.2 & I & I & I \\
\hline EB02 & 3.2 & I & I & 73 & 7.5 & I & I & I \\
\hline EB03 & 6.9 & l & l & 50 & 21.4 & I & I & I \\
\hline ЕH01 & 1.6 & 30 & 8.4 & 60 & 6.2 & 0.7 & 0.5 & I \\
\hline ЕH02 & 3.2 & 30 & 7.4 & 64 & 11.0 & 1.5 & 0.5 & I \\
\hline EH03 & 6.9 & 30 & 8.4 & 48 & 27.1 & 3.2 & 0.6 & I \\
\hline EH04 & 1.6 & 77 & 0.9 & 96 & 1.3 & 1.3 & 0.8 & I \\
\hline EH05 & 3.2 & 77 & 0.9 & 88 & 4.2 & 4.2 & 0.9 & l \\
\hline ЕH06 & 6.9 & 77 & 0.9 & 57 & 14.7 & 14.7 & 1.35 & 11 \\
\hline ЕH07 & 3.2 & 136 & 0.17 & 86 & 3.2 & 17.5 & 1.6 & 25 \\
\hline ЕH08 & 3.2 & 230 & 0.037 & 85 & 3.1 & 84.0 & 2.7 & 50 \\
\hline EH09 & 3.2 & 440 & 0.0053 & 93 & 2.2 & 407.4 & 4.7 & 119 \\
\hline
\end{tabular}

${ }^{a}$ Determined using equation (2). ${ }^{\mathrm{b}}$ Maximum number of latex particles that can be close-packed around each silica sphere calculated according to: $N_{\max }=\frac{2 \pi}{\sqrt{3}}\left(\frac{D_{n \text { Silica }}+D_{n \text { Latex }}}{D_{n \text { Silica }}}\right)^{2}$. This last equation only holds for $D_{\text {n Silica }} / D_{\text {n Latex }}>1.2 .^{73,74}$

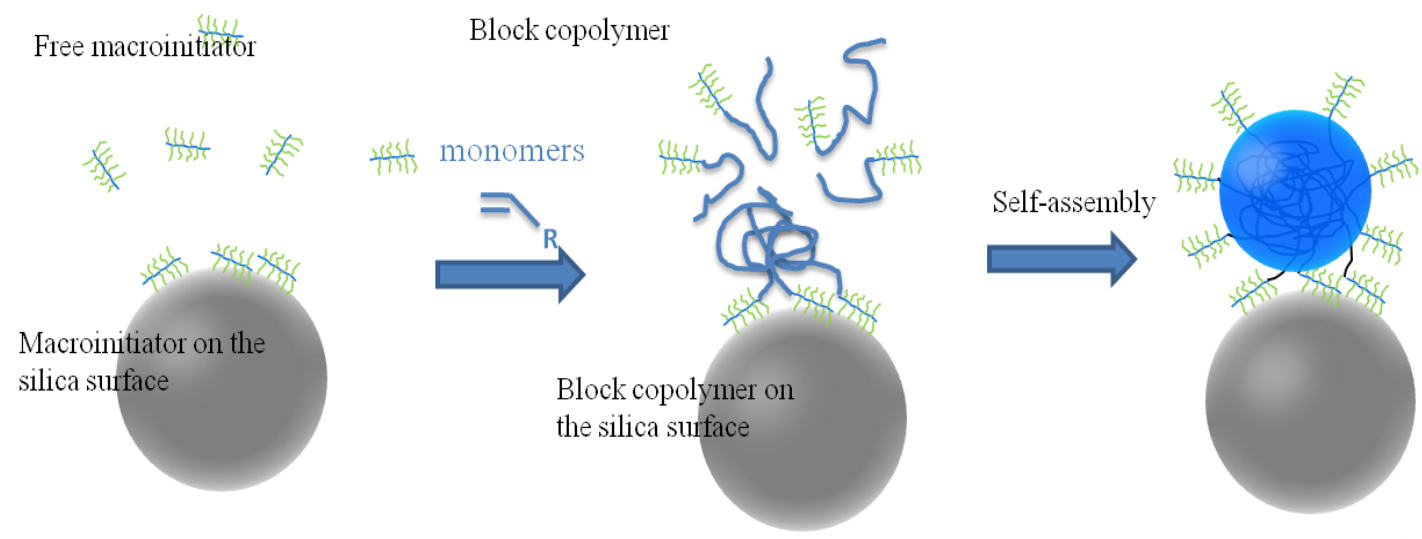

Scheme 2. Schematic illustration of the synthesis of multipod-like silica/polymer particles by NMP-mediated polymerization-induced self-assembly of block copolymers by means of a physically adsorbed brush-type macroalkoxyamine initiator. 


\subsection{Effect of silica particle size}

\subsubsection{Kinetics}

Figure 8 the effect of the silica particle sizes on the evolution of monomer conversion with time for a fixed macroinitiator concentration of $3.2 \mathrm{mmol} \mathrm{L}^{-1}$ over a $\mathrm{pH}$ range of $5.4-6.0$. It is clear that the curves can be divided into two groups with different polymerization rates depending on the amount of hydrochloric acid used to achieve the target $\mathrm{pH}$ value, or in other words, on the ionic strength. For EH02 (performed in the presence of S1 synthesized using the Hartlen process) and EH05 (performed in the presence of the commercial silica sol, S2), the $\mathrm{pH}$ values of the macroalkoxyamine/silica mixtures were 5.4 and 6.0, respectively. Hence, these two suspensions were used directly without any $\mathrm{pH}$ adjustment. In contrast, the use of Stöber silica particles (S3 for EH07, S4 for EH08 and S5 for EH09) required the addition of hydrochloric acid in order to neutralize the residual amount of ammonia and adjust the $\mathrm{pH}$ value to 6.0 , which resulted in a higher ionic strength and hence, in a lower polymerization rate in agreement with our previous work. ${ }^{30}$ Within a group of experiments (EH02/EH05 and EH07/EH08/EH09), the size of the silica particles had no significant effect on the polymerization rate, suggesting that the rate is essentially governed by the events taking place in the water phase, and therefore the physico-chemical properties of the suspension $(\mathrm{pH}$, concentration, ionic strength), rather than the extent of adsorption. 


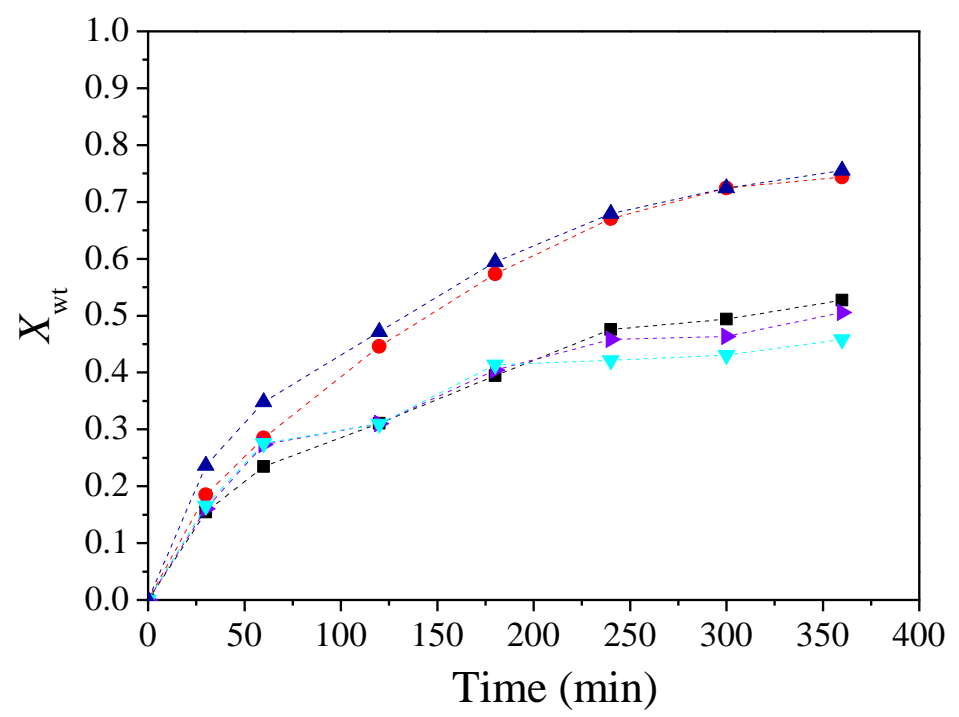

Figure 8. Evolution of monomer conversion with time for the surfactant-free emulsion copolymerizations of BMA and $\mathrm{S}$ in the presence of silica particles with various particle diameters using $3.2 \mathrm{mmol} \mathrm{L}^{-1}$ macroinitiator (B1). EH02 (S1, $30 \mathrm{~nm}, 25 \mathrm{~g} \mathrm{~L}^{-1}$, dark blue $\left.\boldsymbol{\Delta}\right)$, EH05 (S2, 77 nm, $50 \mathrm{~g} \mathrm{~L}^{-1}$, red •), EH07 (S3, 136 nm, $50 \mathrm{~g} \mathrm{~L}^{-1}$, black $\left.\mathbf{\square}\right)$, EH08 (S4, $230 \mathrm{~nm}$, $50 \mathrm{~g} \mathrm{~L}^{-1}$, purple $)$ and EH09 (S5, $440 \mathrm{~nm}, 50 \mathrm{~g} \mathrm{~L}^{-1}$, light blue $\nabla$ ).

\subsubsection{Particle morphology}

Figure 9 the TEM images of the hybrid particles obtained for varying silica particle sizes and a fixed macroinitiator concentration of $3.2 \mathrm{mmol} \mathrm{L}^{-1}$ for four of the five experiments discussed above at a fixed silica concentration of $50 \mathrm{~g} \mathrm{~L}^{-1}$. The morphology evolved from daisy- to multipod- and then raspberry-like upon increasing the silica particle size from $77 \mathrm{~nm}$ to $440 \mathrm{~nm}$. As the silica concentration was kept constant in all the experiments, increasing the silica particle size led to a decrease of the silica particle number, and hence of the total available surface area (Table 3). When the number of silica particles was much smaller than the number of self-assembled latex particles (EH09), the polymer nodules covered the entire silica surface and raspberry-like particles were obtained as shown at the bottom right of 
Figure 9. This assumption was confirmed by cryo-SEM observation (Figure 10), which provided clear evidence of the presence of latex particles surrounding the silica spheres. As expected, increasing the size of the silica particles also led to the formation of more free latex particles, as there was a higher amount of free macroinitiator in the water and less surface area to capture all the resulting block copolymers. Those free latex particles are also clearly visible in the SEM image of Figure 10, forming a dense layer covering the sample background.

Table 3 shows that the number of nucleated polymer nodules slightly decreased from approximately $7.5 \times 10^{17}$ particles $\mathrm{L}^{-1}$ in the absence of silica to around $3 \times 10^{17} \mathrm{~L}^{-1}$ for experiments EH07, EH08 and EH09 performed in the presence of silica. This decrease in particle number may be accounted for by the increase of ionic strength mentioned above. Besides, there is no significant influence of the silica particle diameter on the sizes of either the polymer nodules or the free latex particles, which are very close to each other. Consequently, the maximum number of latex particles that can be accommodated around each silica particle, $\mathrm{N}_{\max }$, solely depends on the silica particle size and increases with increasing silica diameter. As shown in Table 3, the $\mathrm{N}_{\text {Latex }} / \mathrm{N}_{\text {Silica }}$ ratio also increases with increasing the silica particles size and is much higher than the theoretical number of latex particles that can be close packed (with hexagonal symmetry) on each silica sphere. ${ }^{74}$ This, together with the concentration of free macroinitiator, explains the high amount of free latex particles observed in the TEM images of Figure 9 upon increasing the silica particle size. 


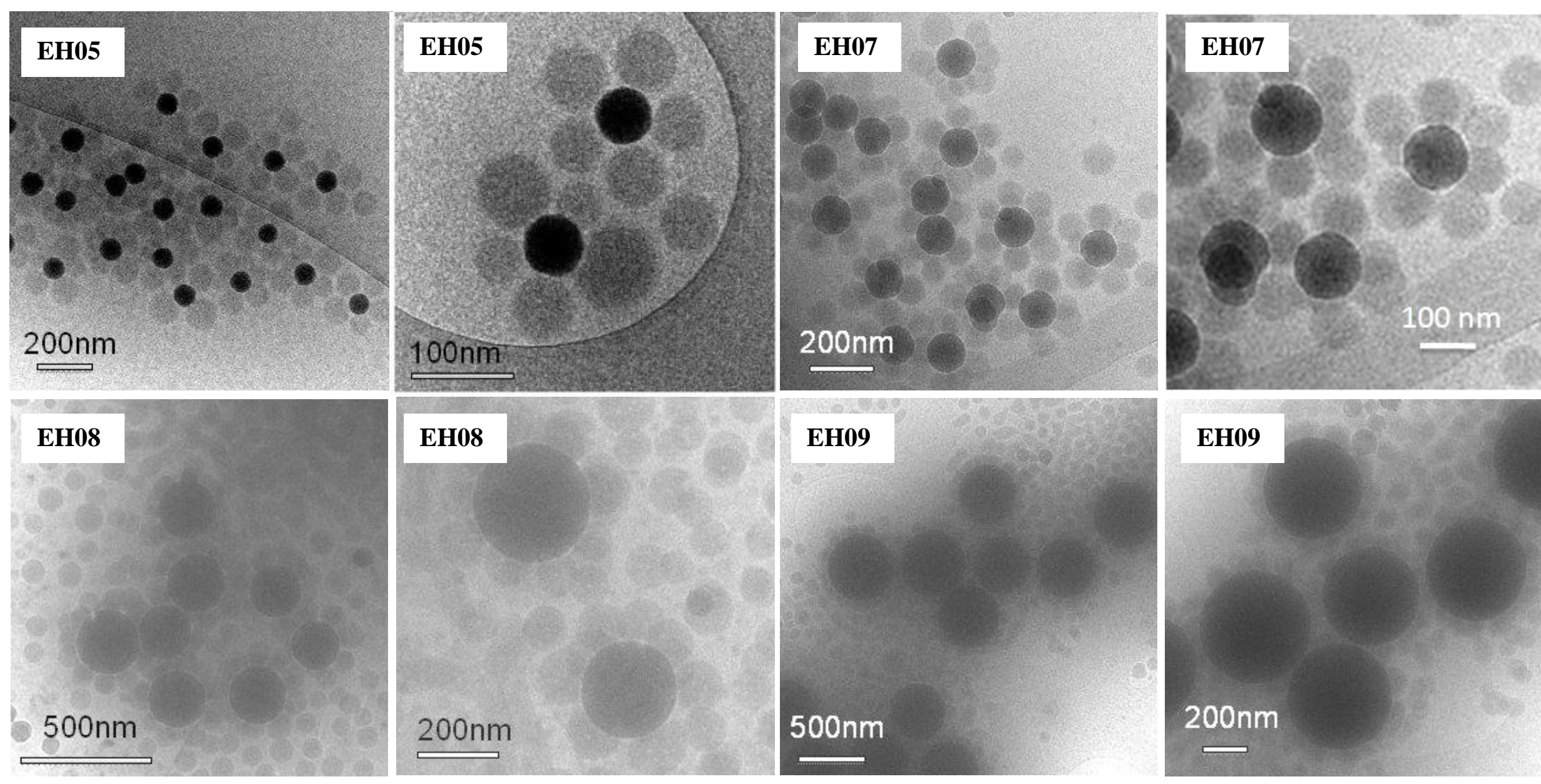

Figure 9. Cryo-TEM images of the final multipod-like silica/polymer latex particles obtained by surfactant-free emulsion copolymerization of

$\mathrm{BMA}$ and $\mathrm{S}$ in the presence of a fixed amount of silica particles with increasing particle diameters using $\mathrm{P}\left[\left(\mathrm{PEOMA}_{950}\right)_{12}-c o-\mathrm{S}_{1}\right]-\mathrm{SG} 1$ as macroinitiator (B1, $\left.3.2 \mathrm{mmol} \mathrm{L}^{-1}\right)$. EH05 (S2, $\left.77 \mathrm{~nm}\right)$, EH07 (S3, $\left.136 \mathrm{~nm}\right)$, EH08 (S4, $\left.230 \mathrm{~nm}\right)$ and EH09 (S5, $\left.440 \mathrm{~nm}\right)$. 


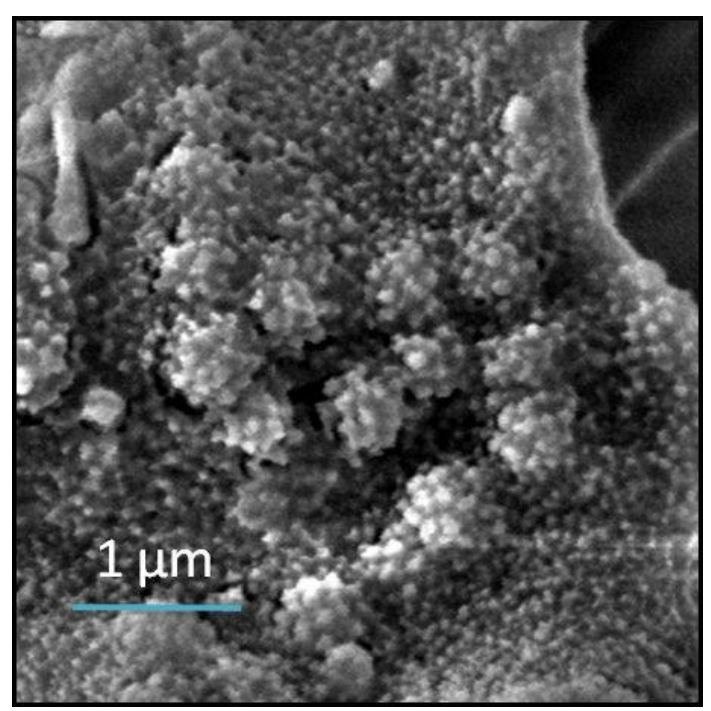

Figure 10. Cryo-SEM image of the raspberry-like silica/polymer hybrid particles synthesized in the presence of $440 \mathrm{~nm}$ diameter silica particles using $\mathrm{P}\left[\left(\mathrm{PEOMA}_{950}\right)_{12}-c o-\mathrm{S}_{1}\right]-\mathrm{SG} 1$ as macroinitiator (B1, $3.2 \mathrm{mmol} \mathrm{L}^{-1}$, EH09 in Table 2).

\section{CONCLUSIONS}

In summary, we have investigated the self-assembly behavior of $\mathrm{P}(\mathrm{PEOMA}-c o-\mathrm{S})-b-\mathrm{P}(\mathrm{BMA}-$ $c o-S)$ block copolymers at the surface of silica particles via PISA in aqueous emulsion. A PEO-based brush-like macroalkoxyamine initiator was first adsorbed at the silica surface, and further used to initiate the growth of the hydrophobic block through nitroxide-mediated emulsion polymerization. The polymerizations showed kinetic profiles and living characteristics similar to the ones reported in our previous work in the absence of silica under the same conditions. Although the polymer chains were not well controlled (high molar mass dispersities and poor agreement between the targeted and experimental values), the shift of the SEC traces towards higher molar mass with increasing conversions indicated successful formation of block copolymers. Silica/polymer hybrid particles with dumbbell-, raspberryand daisy-shaped morphologies were successfully achieved by this surface-PISA process 
depending on the silica particle size and the macroinitiator concentration. This last parameter provided an unprecedented way to tune the multipod-like morphology independently from the silica particle size. To the best of our knowledge, this is the first report on the synthesis of multipod-like silica/polymer particles by nitroxide-mediated polymerization-induced selfassembly of block copolymers in aqueous dispersed media.

\section{SUPPORTING INFORMATION}

Carbon contents of the supernatant solutions determined by elemental analysis and adsorbed amounts of the macroalkoxyamine initiator on the Klebosol silica sol. This information is available free of charge via the Internet at http://pubs.acs.org/.

\section{ACKNOWLEDGMENTS}

The financial support from the Chinese Scholarship Council is greatly acknowledged. The authors would like to thank Olivier Boyron (C2P2, LCPP Team) for his help concerning SEC analyses. They also thank Arkema for kindly providing the BlockBuilder initiator and the

SG1 nitroxide. Bernadette Charleux thanks the Institut Universitaire de France for her nomination as senior member.

\section{REFERENCES}

1. Nehl, C. L.; Liao, H.; Hafner, J. H. Nano Lett. 2006, 6, 683-688.

2. Cozzoli, P. D.; Pellegrino, T.; Manna, L. Chem. Soc. Rev. 2006, 35, 1185-1208.

3. Li, F.; Yoo, W. C.; Beernink, M. B.; Stein, A. J. Am. Chem. Soc. 2009, 131, 1854818555 
4. Cheng, K.; Kothapalli, S-R.; Liu, H.; Koh, A. L.; Jokerst, J. V.; Jiang, H.; Yang, M.; Li, J.; Levi, J.; Wu, J. C.; Gambhir, S. S.; Cheng, Z. J. Am. Chem. Soc. 2014, 136, 3560-3571.

5. Sajanlal, P. R.; Sreeprasad, T. S.; Samal, A. K.; Pradeep, T. Nano Reviews 2011, 2, 5883-5944.

6. Sacanna, S.; Pine, D. J. Curr. Opin. Colloid Interf. Sci. 2011, 16, 96-105.

7. Chen, Q.; Yan, J.; Zhang, J.; Bae, S. C.; Granick, S. Langmuir 2012, 28, 13555-13561.

8. Duguet, E.; Desert, A.; Perro, A.; Ravaine, S. Chem. Soc. Rev. 2011, 40, 941-960.

9. a) Sheu, H. R.; El-Aasser, M. S.; Vanderhoff, J. W. J. Polym. Sci., Part A: Polym. Chem. 1990, 28, 629-651. b) Mock, E. B.; De Bruyn, H.; Hawkett, B. S.; Gilbert, R. G.; Zukoski, C. F. Langmuir 2006, 22, 4037-4043.

10. Kraft, D. J.; Vlug, W. S.; Kats, C. M. V.; Blaaderen, A. V.; Imhof, A.; Kegel, W. K. S. J. Am. Chem. Soc. 2009, 131, 1182-1186.

11. Park, J. G.; Forster, J. D.; Dufresne, E. R. J. Am. Chem. Soc. 2010, 132, 5960-5961

12. Velev, O. D.; Furusawa, K.; Nagayama, K. Langmuir 1996, 12, 2374-2384.

13. Manoharan, V.; Elsesser, M.; Pine, D. Science 2003, 301, 483-487.

14. Wagner, C. S.; Fischer, B.; May, M.; Wittemann, A. Colloid Polym. Sci. 2010, 288, 487-498.

15. a) Cho, Y-S.; Yi, G-R.; Chung, Y. S.; Park, S. B.; Yang, S-M. Langmuir 2007, 23, 12079-12085. b) Paquet, C.; Page, L.; Kell, A.; Simard, B. Langmuir 2010, 26, 53885396.

16. Cho, Y.; Yi, G.; Lim, J.; Kim, S.; Manoharan, V.; Pine, D.; Yang, S. J. Am. Chem. Soc. 2005, 127, 15968-15975.

17. a) Zou, H.; Wu, S.; Shen, J. Chem. Rev. 2008, 108, 3893-3957. b) Bourgeat-Lami, E.; Lansalot, M. Adv. Polym. Sci. 2010, 233, 53-123.

18. a) Reculusa, S.; Mingotaud, C.; Bourgeat-Lami, E.; Duguet, E.; Ravaine, S. Nano Lett. 2004, 4, 1677-1682. b) Perro, A.; Reculusa, S.; Bourgeat-Lami, E.; Duguet, E.; Ravaine, S. Colloids and Surfaces, A., Physicochem. Eng. Aspects 2006, 284, 78-83.

19. Perro, A.; Duguet, E.; Lambert, O.; Taveau, J-C.; Bourgeat-Lami, E.; Ravaine, S. Angew. Chem. Int. Ed. 2009, 48, 361-365.

20. a) Reculusa, S.; Poncet-Legrand, C.; Ravaine, S.; Mingotaud, C.; Duguet, E.; Bourgeat-Lami, E. Chem. Mater. 2002, 14, 2354-2359. b) Reculusa, S.; Poncet- 
Legrand, C.; Perro, A.; Duguet, E.; Bourgeat-Lami, E.; Mingotaud, C.; Ravaine, C. Chem. Mater. 2005, 17, 3338-3344.

21. Parvole, J.; Chaduc, I.; Ako, K.; Spalla, O.; Thill, A.; Ravaine, S.; Duguet, E.; Lansalot, M.; Bourgeat-Lami, E. Macromolecules 2012, 45, 7009-7018.

22. Désert, A.; Chaduc, I.; Fouilloux, S.; Taveau, J.-C.; Lambert, O.; Lansalot, M.; Bourgeat-Lami, E.; Thill, A.; Spalla, O.; Ravaine S.; Duguet, E. Polym. Chem. 2012, $3,1130-1132$.

23. Charleux, B.; D’Agosto, F.; Delaittre, G. Adv. Polym. Sci. 2010, 233, 125-183.

24. Charleux, B.; Delaittre, G.; Rieger, J.; D'Agosto, F. Macromolecules 2012, 45, 67536765 .

25. Nicolas, J.; Guillaneuf, Y.; Lefay, C.; Bertin, D.; Gigmes, D.; Charleux, B. Prog. Polym. Sci. 2013, 38, 63-235.

26. a) Delaittre, G.; Nicolas, J.; Lefay, C.; Save, M.; Charleux, B. Chem. Commun. 2005, 615-616. b) Delaittre, G.; Nicolas, J.; Lefay, C.; Save, M.; Charleux, B. Soft Matter 2006, 2, 223-231. c) Delaittre, G.; Dire, C.; Rieger, J.; Putaux, J.-L.; Charleux, B. Chem. Commun. 2009, 2887-2889.

27. Dire, C.; Magnet, S.; Couvreur, L.; Charleux, B. Macromolecules 2009, 42, 95-103.

28. a) Brusseau, S.; Belleney, J.; Magnet, S.; Couvreur, L.; Charleux, B. Polym. Chem. 2010, 1, 720-729. b) Brusseau, S.; D’Agosto, F.; Magnet, S.; Couvreur, L.; Chamignon, C.; Charleux, B. Macromolecules 2011, 44, 5590-5598.

29. Groison, E.; Brusseau, S.; D’Agosto, F.; Magnet, S.; Inoubli, R.; Couvreur, L.; Charleux, B. ACS Macro Lett. 2012, 1, 47-51.

30. Qiao, X. G.; Lansalot, M.; Bourgeat-Lami, E.; Charleux, B. Macromolecules 2013, 46, 4285-4295.

31. a) Ferguson, C. J.; Hughes, R. J.; Nguyen, D.; Pham, B. T. T.; Hawkett, B. S.; Gilbert, R. G.; Serelis, A. K.; Such, C. H. Macromolecules 2002, 35, 9243-9245. b) Ferguson, C. J.; Hughes, R. J.; Nguyen, D.; Pham, B. T. T.; Gilbert, R. G.; Serelis, A. K.; Such, C. H.; Hawkett, B. S. Macromolecules 2005, 38, 2191-2204.

32. a) Rieger, J.; Stoffelbach, F.; Bui, C.; Alaimo, D.; Jérôme, C.; Charleux, B. Macromolecules 2008, 41, 4065-4068. b) Rieger, J.; Osterwinter, G.; Bui, C.; Stoffelbach, F.; Charleux, B. Macromolecules 2009, 42, 5518-5525. c) Rieger, J.; Zhang, W.; Stoffelbach, F.; Charleux, B. Macromolecules 2010, 43, 6302-6310.

33. a) Boissé, S.; Rieger, J.; Belal, K.; Di-Cicco, A.; Beaunier, P.; Li, M.-H.; Charleux, B. Chem. Commun. 2010, 46, 1950-1952. b) Boissé, S.; Rieger, J.; Pembouong, G.; 
Beaunier, P.; Charleux, B. J. Polym. Sci., Part A: Polym. Chem. 2011, 49, 3346-3354.

34. a) Zhang, X.; Boisse, S.; Zhang, W.; Beaunier, P.; D’Agosto, F.; Rieger, J.; Charleux, B. Macromolecules 2011, 44, 4149-4158. b) Zhang, W.; D’Agosto, F.; Boyron, O.; Rieger, J.; Charleux, B. Macromolecules 2011, 44, 7584-7593.

35. Chaduc, I.; Zhang, W.; Rieger, J.; Lansalot, M.; D’Agosto, F.; Charleux, B. Macromol. Rapid Commun. 2011, 32, 1270-1276.

36. Xu, J.; Wang, X.; Zhang, Y.; Zhang, W.; Sun, P. J. Polym. Sci., Part A: Polym. Chem. 2012, 50, 2484-2498.

37. Chaduc, I.; Girod, M.; Antoine, R.; Charleux, B.; D'Agosto, F.; Lansalot, M. Macromolecules 2012, 45, 5881-5893.

38. Zhang, X.; Rieger, J.; Charleux, B. Polym. Chem. 2012, 3, 1502-1509.

39. Chaduc, I.; Crepet, A.; Boyron, O.; Charleux, B.; D’Agosto, F.; Lansalot, M. Macromolecules 2013, 46, 6013-6023.

40. Zhang, W.; D'Agosto, F.; Dugas, P.-Y.; Rieger, J.; Charleux, B. Polymer 2013, 54, 2011-2019.

41. Chenal, M.; Bouteiller, L.; Rieger, J. Polym. Chem. 2013, 4, 752-762.

42. Xu, J.; Xiao, X.; Zhang, Y.; Zhang, W.; Sun, P. J. Polym. Sci., Part A: Polym. Chem. 2013, 51, 1147-1161.

43. Velasquez, E.; Rieger, J.; Stoffelbach, F.; Charleux, B.; D’Agosto, F.; Lansalot, M.; Dufils, P.-E.; Vinas, J. Polymer 2013, 54, 6547-6554.

44. Binauld, S.; Delafresnaye, L.; Charleux, B.; D’Agosto, F.; Lansalot, M. Macromolecules 2014, 47, 3461-3472.

45. Carlsson, L.; Fall, A.; Chaduc, I.; Wagberg, L.; Charleux, B.; Malmstrom, E.; D'Agosto, F.; Lansalot, M.; Carlmark, A. Polym. Chem. 2014, 5, 6076-6086

46. Cunningham, V. J.; Alswieleh, A. M.; Thompson, K. L.; Williams, M.; Leggett, G. J.; Armes, S. P.; Musa, O. M. Macromolecules 2014, 47, 5613-5623.

47. Ratcliffe, L.; Blanazs, A.; Williams, C.; Brown, S.; Armes, S. P. Polym. Chem. 2014, 5, 3643-3655.

48. Nguyen, D.; Zondanos, H. S.; Farrugia, J. M.; Serelis, A. K.; Such, C. H.; Hawkett, B. S. Langmuir 2008, 24, 2140-2150.

49. Das, P.; Claverie, J. P. J. Polym. Sci., Part A: Polym. Chem. 2012, 50, 2802-2808

50. Ali, S. I.; Heuts, J. P. A.; Hawkett, B. S.; van Herk, A. M. Langmuir 2009, 25, 1052310533. 
51. Zhong, W.; Zeuna, J. N.; Claverie, J. P. J. Polym. Sci., Part A: Polym. Chem. 2012, 50, 4403-4407.

52. Nguyen, D.; Such, C.H.; Hawkett, B. S. J. Polym. Sci. Part A. Polym. Chem. 2013, 51, 250-257.

53. Zgheib, N.; Putaux, J.-L.; Thill, A.; Bourgeat-Lami, E.; D'Agosto, F.; Lansalot, M. Polym. Chem. 2013, 4, 607-614.

54. a) Garnier, J.; Warnant, J.; Lacroix-Desmazes, P.; Dufils, P.-E.; Vinas, J.;

Vanderveken, Y.; van Herk, A. M. Macromol. Rapid Commun. 2012, 33, 1388-1392.

b) Garnier, J.; Warnant, J.; Lacroix-Desmazes, P.; Dufils, P.-E.; Vinas, J.; van Herk, A. J. Colloid Interf. Sci. 2013, 407, 273-281. c) Warnant, J.; Garnier, J.; van Herk, A.; Dufils, P.-E.; Vinas, J.; Lacroix-Desmazes, P. Polym. Chem. 2013, 4, 5656-5663.

55. Rodrigues Guimaraes, T.; de Camargo Chaparro, T.; D'Agosto, F.; Lansalot, M.; Martins Dos Santos, A.; Bourgeat-Lami, E. Polymer Chemistry. DOI: 10.1039/C4PY00362D

56. Hartlen, K. D.; Athanasopoulos, A. P. T.; Kitaev, V. Langmuir 2008, 24, 1714-1720.

57. Fouilloux, S.; Désert, A.; Taché, O.; Spalla, O.; Daillant, J.; Thill, A. J. Colloid Interface Sci. 2010, 346, 79-86.

58. Chang, S. M.; Lee, M.; Kim, W.-S. J. Colloid Interface Sci. 2005, 286, 536-542.

59. Chen, S.-L.; Dong, P.; Yang, G.-H.; Yang, J.-J. J. Colloid Interface Sci. 1996, 180, 237-241.

60. Giesche, H. J. Eur. Ceram. Soc. 1994, 14, 189-204.

61. Stöber, W.; Fink, A.; Bohn, E. J. Colloid Interface Sci. 1968, 26, 62-69.

62. Negrete-Herrera, N.; Putaux, J.-L.; David, L.; Haas, F. D.; Bourgeat-Lami, E. Macromol. Rapid Commun. 2007, 28, 1567-1573.

63. Colloidal Silica: fundamentals and applications. Surfactant Science Series Vol. 31. Bergna, H. E. and Roberts W. O. Eds, CRC Press, Taylor \& Francis Group, New York, 2006.

64. Rubio, J.; Kitchener, J. A. J. Colloid Interface Sci. 1976, 57, 132-142.

65. Voronin, E. F.; Gun'ko, V. M.; Guzenko, N. V.; Pakhlov, E. M.; Nosach, L. V.; Leboda, R.; Skubiszewska-Zieba, J.; Malysheva, M. L.; Borysenko, M. V.; Chuiko, A. A. J. Colloid Interf. Sci. 2004, 279, 326-340.

66. Flood, C.; Cosgrove, T.; Howell, I.; Revell, P. Langmuir 2006, 22, 6923-6930.

67. Olanya, G.; Iruthayaraj, J.; Poptoshev, E.; Makuska, R.; Vareikis, A.; Claesson, P. M. Langmuir 2008, 24, 5341-5349. 
68. Linse, P.; Claesson, P. M. Macromolecules 2010, 43, 2076-2083.

69. Naderi, A.; Iruthayaraj, J.; Pettersson, T.; Makuska, R.; Claesson, P. M. Langmuir 2008, 24, 6676-6682.

70. Sheiko, S. S.; Sumerlin, B. S.; Matyjaszewski, K. Prog. Polym. Sci. 2008, 33, 759785

71. Liu, X.; Dedinaite, A.; Rutland, M.; Thormann, E.; Visnevskij, C.; Makuska, R.; Claesson, P. M. Langmuir 2012, 28, 15537-15547.

72. Fischer, H. Chem. Rev. 2001, 101, 3581-3610.

73. Mansfield, M. L.; Rakesh, L.; Tomalia, D. A. J. Chem. Phys. 1996, 105, 3245-3249.

74. Uppuluri, S.; Swanson, D. R.; Piehler, L. T.; Li, J.; Hagnauer, G. L.; Tomalia, D. A. Adv. Mater. 2000, 12, 796-800.

75. Taveau, J.-C.; Nguyen, D.; Perro, A.; Ravaine, S.; Duguet, E.; Lambert, O. Soft Matter 2008, 4, 311-315. 
Synthesis of multipod-like silica/polymer latex particles via nitroxide-mediated polymerization-induced self-assembly of amphiphilic block copolymers

X. G. Qiao, P-Y. Dugas, B. Charleux, M. Lansalot, E. Bourgeat-Lami*

Table of Contents graphic

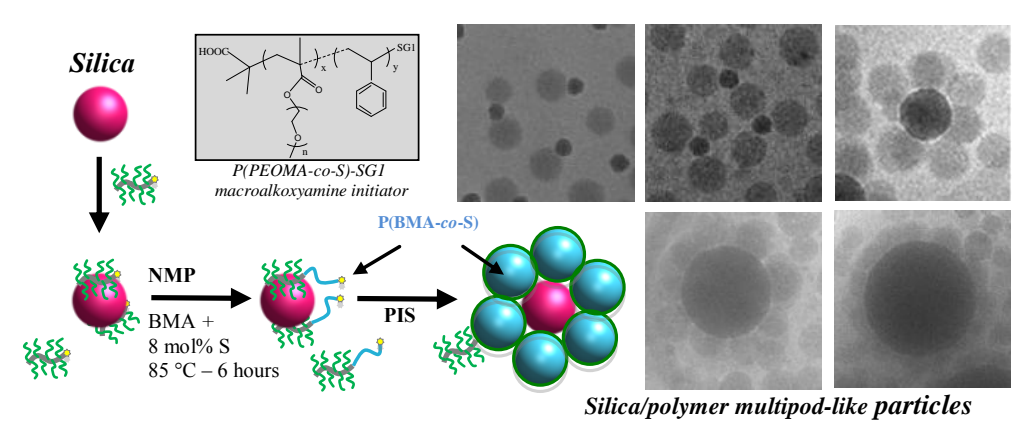

